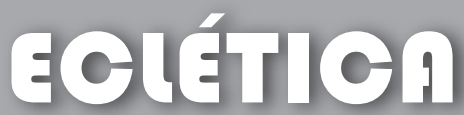 química
}

\section{BIORREMEDIAÇÃO DE SOLOS CONTAMINADOS POR PETRÓLEO E SEUS DERIVADOS}

\author{
Juliano de Almeida Andrade ${ }^{1}$, Fabio Augusto 2 \& Isabel Cristina Sales Fontes Jardim ${ }^{3}$ \\ ${ }^{1}$ Laboratório de Pesquisas em Cromatografia Líquida (LABCROM), Departamento de Química Analítica (DQA), Instituto de Química \\ (IQ), Universidade Estadual de Campinas (UNICAMP), Caixa Postal 6154, CEP 13084-971, Campinas, SP, Brasil. E-mail: jaa1000@ \\ gmail.com. \\ ${ }^{2}$ Laboratório de Cromatografia Gasosa (LCG), DQA, IQ, UNICAMP. \\ ${ }^{3}$ LABCROM, DQA, IQ, UNICAMP.
}

\begin{abstract}
Resumo: Em vista da eficiência comprovada da biorremediação na degradação de compostos tóxicos ao ser humano, como o benzeno, tolueno, etilbenzeno e xilenos (BTEX), diversas empresas, principalmente as relacionadas com consultorias e remediação ambiental, têm despertado grandes interesses pela implantação da biorremediação como opção para a reabilitação de áreas contaminadas. Em países desenvolvidos, como os Estados Unidos, Canadá e vários países da Europa, a técnica bioquímica de remediação vem sendo amplamente utilizada em trabalhos que se baseiam, por exemplo, no tratamento de solos contaminados por hidrocarbonetos de petróleo. Porém, ao contrário do que se tem notado nesses países, no Brasil, os projetos de biorremediação ainda estão no campo da teoria, com poucos casos práticos, embora exista uma probabilidade real de expansão. A esse despeito, uma das maiores pertinências dessa revisão é elucidar as vantagens que essa técnica pode oferecer quando é utilizada para a degradação de compostos, como os BTEX, em solos tipicamente brasileiros, cujas características físico-químicas contribuem, em muito, para a degradação desses contaminantes. Nessa conjuntura, pesquisas revelam que os fatores ambientais (como teores de umidade e oxigênio) e a disponibilidade de nutrientes nos solos, além das condições climáticas do Brasil, são bastante adequadas para o emprego dessa técnica. Isso pode trazer como vantagens, ótima relação custo-benefício e maior eficiência na degradação de compostos tóxicos e recalcitrantes frente à maioria das técnicas convencionais de remediação. Em síntese, a presente revisão busca enfocar o estado da arte das técnicas de biorremediação de contaminantes em solos, apresentando as mais atuais e recentes aplicações e inovações, tanto no âmbito nacional quanto no internacional.
\end{abstract}

Termos de indexação: biorremediação; degradação; contaminantes; hidrocarbonetos de petróleo - BTEX; solos; tratamento de áreas contaminadas.

CONTAMINAÇÃO DE SOLOS POR PETRÓLEO E SEUS DERIVADOS

O mundo atual está cada vez mais dependente do petróleo e de seus derivados para a manutenção de sua atividade industrial. Durante a exploração, o refino, o transporte e as operações de armazenamento do petróleo e/ou de seus deri- vados podem vir a ocorrer derramamentos acidentais ocasionando a contaminação de solos, rios, etc. Tais ocorrências vêm motivando, principalmente, a realização de pesquisas relacionadas com a remediação de sítios contaminados (Aislabie et al., 2004; Marín et al., 2006).

O que se tem notado, nas duas últimas décadas, é que a poluição causada por petróleo e 
seus derivados tem sido um dos principais problemas ao meio ambiente. Quando ocorre o derramamento de gasolina em solos, por exemplo, uma das principais preocupações é a contaminaça das águas subterâneas, que também podem ção das aguas sub contaminar, especialmente, os aquiferos que são usados como fontes de abastecimento de água para o consumo humano (Custance et al., 1992). Os frequentes derramamentos de petróleo e seus derivados registrados em solos brasileiros vêm motivando o desenvolvimento de novas técnicas que visam, principalmente, a descontaminação dessas matrizes. Diante disso, diversas técnicas, físicas, químicas e biológicas, vêm sendo desenvolvidas para a remoção ou a degradação in-situ ou ex-situ de petróleo derras de seus efeitos sobre o ecossistema, especiathente os tóxicos. Dentre as técnicas desenvolvidas, a "biorrentiça "biomentição" vem se destacando como una a de solos contaminados por petróleo e seus derivados (Bento et al., 2003; Dua et al., 2002; Rahman et al., 2002)

De modo geral, a biorremediação baseia-se na degradação bioquímica dos contaminantes por meio da atividade de microorganismos presentes ou adicionados no local de contamina a (Bernoth a (Beñoth et al., 2000). Neste caso, os tratamentos são basicanente de dois tipos. 1) ex-situ (ou off-site), realizado fora do local onde ocorreu a contaminação e, por isso, é um tratamento que requer a escavação e a remoção do solo contaminado para outro local. A adoção deste procedimento pode resultar em um aumento considerável do custo do processo, porém, não obstante a essa desvantagem, é possível controlar, com maior facilidade, as condicionantes do meio (vide o item "Fatores que influenciam a biodegradabilidade dos contaminantes"), que são consideradas os fatores-chave utilizados no tratamento dos solos; 2) in-situ (ou on-site), 2) in-situ (o don-site), trata local da contaminação. Normalmente, essa opção de biorremediação torna o processo mais atrativo e economicamente viável, quando comparado ao tratamento citado anteriormente. Além disso, o tratamento in-situ, normalmente, acarreta em menores impactos ambientais advindos da remediação da área contaminada (Nano et al., 2003).
Principais contaminantes de petróleo e seus derivados em solos

O petróleo é uma mistura complexa que contém vários compostos, sendo que os hidrocarbonetos cordo co reprentam a fração majoritária. De acordo com a sua origem, as suas composições químicas e as suas propriedades físicas variam de um campo petrolífero para outro. Devido, principalmente, à complexidade dessa mistura, normalmente o tratamento de áreas contaminadas por essas substâncias é bastante difícil e problemático. Em solos contaminados por petróleo e seus derivados, algur

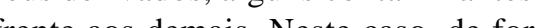
freral, os compostos de interesse que exigem maior preocupação ambiental e que, normalmente, são os principais a serem identificados e quantificado antes e durante um processo de remediação, são benzeno, tolueno, etilbenzeno e xilenos (isômeros: orto-, meta- e para-xileno). Esses compostos, conhecidos também como BTEX, são definidos como hidrocarbonetos monoaromáticos, cujas esruturas moleculares possuem como caractística

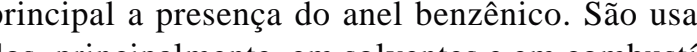
dos, principalmente, em solventes e em combustída gasolina.

Compostos como os BTEX, constituem em um grande problema, não somente no Brasil, mas em todo o mundo. Esses compostos aromáticos são tóxicos tanto ao meio ambiente como ao ser humano, nos quais atuam como depressores do sistema nervoso central e apresentam toxicidade crônica mais significativa que os hidrocarbonetos alifáticos (também presentes no (a) e derivados), mesmo em concentraçoes da ordem de $\mu \mathrm{g} \mathrm{L}^{-1}$ (Watts et al., 2000). O benzeno é reconhecidamente o composto mais tóxico dentre os BTEX e, por isso, pode ser apontado como o agente mais preocupante no tocante à saúde pública. Segundo a Agência Internacional de Pesquisa de Câncer (International Agency for Research on Câncer - IARC), órgão da Organização Mundial da Saúde, o benzeno se classifica no Grupo I, ou seja, é uma substância comprovadamente canceseres human. Assim como a IARC, nos Estas
Unidos, a Agência de Saúde e Segurança Ocupacional (National Institute for Occupational Safety and Health - NIOSH), bem como a Agência de Proteção Ambiental (Environmental Protection Proteção Ambienta (Ém inonm o protection Ageney - EPA) taben incla o benzeno en IARC, 2006; NIOSH, 2006). Daí, a importância considerável em monitorar esses contaminantes considerável em monitorar ess

episódios de contaminações.
Em solos contaminados por petróleo e seus derivados, além dos BTEX, geralmente, outras classes de compostos também são alvos de atenção, como os hidrocarbonetos policíclicos aromáticos (HPA), os compostos orgânicos volátei (COV) totais e os hidrocarbonetos totais de petró(Co (HTP). Os compostos BTEX, HPA e I leo (HTP). Os compostos BTEX, HPA e HTP são escolhidos, principalmente, pela toxicidade, mobilidade e persistencia no neio anbiente, os COV totais, por representarem o total de emissões gasosas, como perdas por volatilização proveniente do derramamento. Assim, qualquer contaminação oriunda dessas fontes merece atenção, não apenas pelo contato direto (como a inalação de vapores) desses compostos indevidamente dispostos no solo, mas também quanto à sua presença em águas utilizadas para o consumo humano.

\section{TIPOS DE TRATAMENTO DE SOLOS}

Objetivo desse tópico é introduzir as técnicas de remediação mais empregadas atualmente no tratamento de solos contaminados por petróleo e seus derivados, que serão descritas brevemente, a seguir. Para isto, será exemplificada cada técnica de remediação: química (oxidação química in-situ), biológica (atenuação natural e biorremediação) e física (extração de vapores no solo). Assim, dentre as formas de tratamento existentes, con base no objeto principal do presente artigo, sobiorremediação será descrita em detalhes.

De modo geral, deve-se salientar que cada é dependente de vánios fatores, a suber: 1) condições físicas, quínicas e tores, a saber. 1) condições físicas, químicas biologicas do local contaminado; 2) concentração do contaminante e; 3) tempo requerido para a degradação ou a remoção do composto alvo, conforme a técnica empregada. Em todos os processos de tratamento existe uma correlação direta entre o tempo requerido para a remediação da área e 0 custo total, como pode ser visto na Figura 1, que mostra a faixa de valor cobrado para a descontaminação de um metro cúbico $\left(\mathrm{m}^{3}\right)$ de solo, usando diferentes técnicas de remediação. 


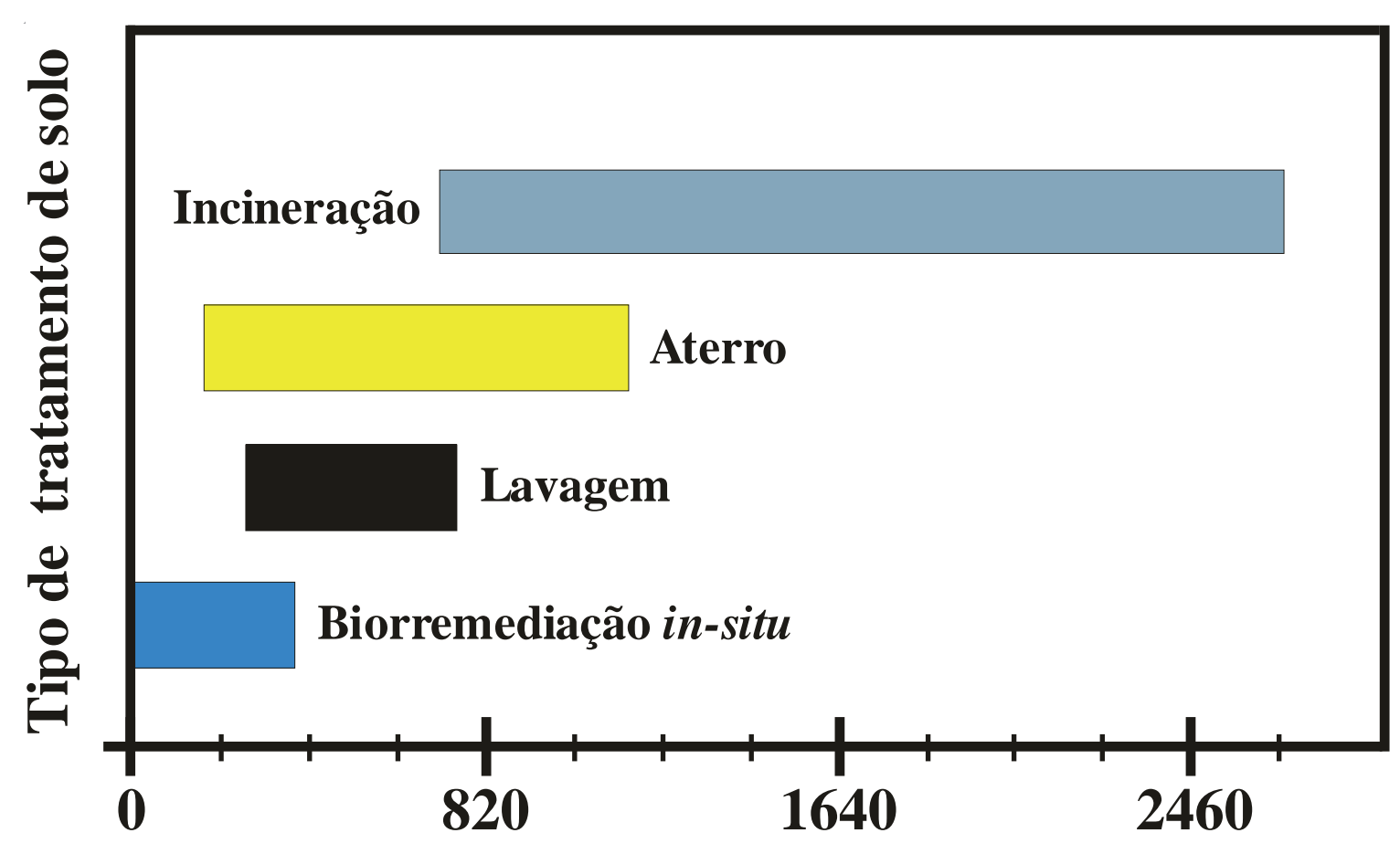

Custo do tratamento por $\mathbf{m}^{3}$ de solo (dólar)

Figura 1. Comparação entre os custos do tratamento de solos empregando diferentes técnicas de remediação (modificado de EPA)

A análise da Figura 1 permite observar que biorremediação é a técnica que apresenta o custo de tratamento mais baixo quando comparado às demais. A incineração caracteriza-se por apresentar custos maiores relacionados ao tratamento de solos e, consequentemente, à inviabilidade do processo, dependendo do volume de solo a ser tratado. Utilizando a incineraç̃̃o como opşão de tratamento, dependendo do tipo de conposto a ser tratame destrifin, o custo total do processo pode chegar, aproximadamente, em 2.665 dólares para cada $\mathrm{m}^{3}$ de solo tratado. Salienta-se, porem, que aqui o objetivo não é desprezar e nem desmerecer uma técnica ou outra e, sim, elucidar algumas vantagens apresentadas na utilização da biorremediação. Sendo que esta, assim como qualquer outra técnica, traz diversas vantagens e limitações. Por isso, sugere-se que cada caso seja analisado criteriosa e individualmente, principalmente, quando tratar da tomada de decisão para a escolha da técnica de remediação a ser empregada.

\section{Oxidação química in-situ}

A oxidação química in-situ, consiste na injeção de produtos químicos reativos diretamente no local contaminado, com o objetivo de degradar rapidamente os con que promovem a oxidação ou redução das espécies de interesse presentes em uma determinada área. Também conhecido como ISCO (In-Situ Chemical Oxidation), segundo Brown (2003), esse processo é mais frequentemente empregado em locais contendo concentrações elevadas do contaminante, geralmente, presentes na fonte e na "pluma" de contaminação. A pluma é definida como o local onde estão distribuídos os contaminantes, normalmente lançados a parti de uma fonte pontul. A extensão e a expansão da pexpansão lio ple ma com o auxílio de cujos dados são obtidos após a caracterização do
solo (como a permeabilidade), da água subterrâ- nea (como o gradiente hidráulico, a velocidade e o tipo de recarga) e dos contaminantes que estão sendo despejados. Em áreas altamente contaminadas a oxidação química pode ser uma etapa de pré-tratamento que promove methores condiça prét para o enpro de outras técnicas, cono os tratamentos biológicos. Destes, fazem parte a biorremediação e a atenuação natural monitorada ou acelerada, que geralmente são técnicas menos onerosas que as químicas (EPA, 2001a e 2004a).

Dentre os processos químicos emergentes para o tratamento de solos, os processos oxidativos avançados (POA) destacam-se como uma alternativa promissora, pois, envolvem a geração de espécies químicas radicalares e altamente oxidantes, cono o radical hidroxila (OH'). Esses radicais s̃o capazes de destuurta (OH). Esses raem derados de difícil degradação, como os hidrocarbonetos bonetos de petróleo. Os POA, em função de suas eficiências comprovadas na degradação de contaminantes de petróleo e seus derivados, representam, atualmente, uma alternativa importante para a mitigação de problemas ambientais (Andrade, 2005). Dentre as técnicas químicas relacionadas com os POA, as mais utilizadas são: reagente de Fenton $\left(\mathrm{H}_{2} \mathrm{O}_{2} / \mathrm{Fe}^{2+} / \mathrm{H}^{+}\right)$, persulfoto $\left(\mathrm{S}_{2} \mathrm{O}_{3}^{2-}\right)$, perFenton $\left.\left(\mathrm{H}_{2} \mathrm{O}_{2} \mathrm{~F}^{-}\right) \mathrm{H}^{-}\right)$, $\left.\mathrm{O}_{3} / \mathrm{OH} ; \mathrm{O}_{3} / \mathrm{H}_{2} \mathrm{O}_{2}\right), \mathrm{H}_{2} \mathrm{O} / \mathrm{UV}$ e fotocatálise hetero-

$\left.\mathrm{O}_{3} /-\mathrm{OH} ; \mathrm{O}_{3} / \mathrm{H}_{2} \mathrm{O}_{2}\right)$,
gênea $\left(\mathrm{TiO}_{2} / \mathrm{UV}\right)$.

regente de Fenton destaca-se frente ao demais POA, por ser capaz de gerar o radical $\mathrm{OH}^{*}$ mesmo na ausência de luz, ao contrário dos processos que utilizam a radiação ultravioleta para catalisar a reação. Além dessa vantagem, esse processo, em função da sua natureza homogênea, é de fácil implementação, mesmo para a remediação de minizes complexas, como os solos e as águas de matrizes con (Ande 2005). No caso as águas subterraneas (Anco particular da remediação de solos, a presença de espécies de ferro de origem natural, encontradas na maiori desses compartimentos ambientais, permite a utilização do reagente de Fenton apenas por adição do agente oxidante no sistema (Peralta-Zamora \& Tiburtius, 2004). Neste caso, dentre os oxidantes disponíveis (ozônio, peróxidos de hidrogênio e de cálcio, persulfato de sódio, permanganatos de sódio e de potássio), o mais empregado é o peróxido

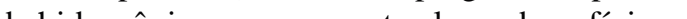

relação aos demais oxidantes, como reatividade elevada, custos baixos e facilidades no manuseio e na aplicação.

Adicionalmente, em pesquisas voltadas para a otimização do reagente de Fenton na remediaça de matizes contaninadas por hidrocabonetos de petróleo, Andrade (2005) denstra que é possivel aum, Andrade (2005) demonstra gente na degração de no comple reacional. Este processo for denominado pelo autor de reagente de Fenton modificado (RFM). A partir desses estudos, desenvolveu-se um reagente registrado como FENTOX $^{\circledR}$ (patente de invenção PI-0501652-5), que apresenta cinética de reação bastante elevada na degradação de contaminantes organicos, como os BTEX. Segundo o autor, a adição de comple xantes permite que a degração de complos recalcitrante, mis da e da e acelerada. Além disso, o processo traz como principal vantagem frente ao reagente de Fenton convencional, a possibilidade de trabalhar en matrizes ambientais sem que seja necessário o condicionamento adequado do local, previamente à aplicação dos reagentes. Ressalta-se que, para que o reagente de Fenton convencional tenha efipara valores próximos a 3,0 (Andrade, 2005).

\section{Atenuação natural}

O termo "atenuação natural" tem sido empregado para descrever a remediação passiva de solo que envolve a ocorrência de diversos processos, de origens naturais, como a biodegradação, a volatilização, naturais, como a biodegradação, ção, promovidos na subsuperfície. Dentre estes, somente a biodegradação, facilitada por microorganismos, destrói fisicamente os contaminantes de interesse. Os demais processos citados envolvem, basicamente, a transferência dos contaminantes de um local para outro ou a retenço do contannante, no caso do processo de sorç̃o. A principal vantagem do processo de a de şa no na mesmo sem processo de atenuaçăo natural é que, a adequ ça de quater

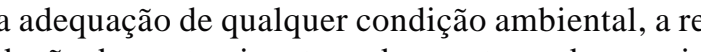
dução do contaminante pode acontecer de maneir 
eficiente e contínua. Isso ocorre devido, principalmente, ao processo de adaptação natural da microbiota nativa existente no solo impactado. Neste caso, esses microorganismos passam a utiliza em seus metabolismos os compostos orgânicos poluentes como fontes de carbono, provocando, então, a redução das concentrações dessas substâncias ao longo do tempo (Robb \& Moyer, 2001). Além disso, o solo contaminado está sujeito aos processos intempéricos de origem natural, nos quais, não somente os processos biológicos (como o processo descrito anteriormente), mas também os físicos e químicos, como a "lixiviação" (processo através do qual ocorre o arraste vertical, pela infiltração da água, de partículas, dissolvidas ou em suspensão, da superfície do solo para as camadas mais profundas) e a volatilização, podem estar envolvidos na redução da concentração do poluente no solo.

A utilização desse processo, como opção principal de remediação, requer algumas ressalvas, haja vista que as condições do meio, inclusive o tipo e a concentração dos contaminantes, podem não contribuir para a redução de substâncias tóxicas e recalcitrantes e, consequentemente, aumentam os riscos de contaminação de pessoas e animis. Por esses molivos, o enprego da a ção notura é permitic ção natural é pernitido e até reconendado, desde que sejam respeitados os resultados obtidos em estudos preliminares sobre a avaliação de risco da exposição da população, elaborada dentro de um cenário real para o uso futuro da área. Normalmente, processos de atenuação natural costumam durar de meses a anos. Por isso, o tempo e a porcentagem de degradação dos contaminantes podem ser muito lentos e até imprevisíveis. É justamente por essa consideraça aue, na maiora dos casos, é necesś́ í que esse processo de tra dos casos é necessátio que esse processo de tratamento seja monitora ligorosa eperiodicamente. Este processo, denominado de "atenuação natural monitorada" (ANM), éun dos mais utilizados nos EUA para a redução do impacto ambiental causado por contaminações de solos com compostos orgânicos.

Devido aos custos elevados envolvidos na remediação de áreas contaminadas, a atenuação natural com monitoramento tem sido adotada como uma possibilidade de intervenção em locais contaminados por substâncias orgânicas biode- gradáveis, nas condições naturais do meio. Esta alternativa baseia-se na capacidade de atenuação natural de contaminantes, no solo e nas águas orre durante um ongo período de tempo, no qual não devem ocorrer riscos à saúde pública, ao meio ambiente e aos demais bens a proteger. A adoção da técnica deve ser precedida de um estudo criterioso que inclua a previsão da evolução das plumas de contaminação, a metodologia de avaliação de risco e o monitoramento durante o período necessário para que se atinjam as metas de remediação desejáveis. Apesar disso, considerando principalmente o tempo necessário para a reabilitação da área, a ANM pode ser onerosa, gerando custos significativos,

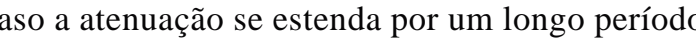
de tempo. Casos como este, comumente, exigem tratamento in-situ ou ex-situ do solo impactado (EPA, 2004b)

\section{Extração de vapores no solo (SVE)}

A extração de vapores no solo, também conhecida como SVE (Soil Vapor Extraction), é uma técnica de remediação comumente empregada no tratamento de solos contaminados, porém, deve-se ressaltar que essa técnica é aplicada somente à "zona não-saturada” (zona que se situa imedia"zmente abaixo da superfície topográfica e acima do nível freático, onde os espaços ence as partículas estão diculas estäo parciallnerte preenchidos por gases, por água A água contida nessa zopor de água, por agua. A água contida nessa zona encontra-se a pressão atmosférica, podendo ser utilizada pelas raízes das plantas ou contribuir para o aumento das reservas de água subterrânea). De modo geral, a SVE baseia-se na aplicação de vácuo em pontos estratégicos do solo, a fim de induzir o fluxo controlado de ar e, então, remover os contaminantes presentes no solo, sobretudo, nas regiões da subsuperfície. Nessa técnica, os gases deven, obigation

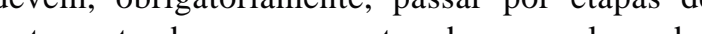
tratamento de vapores, antes de serem lançados para a atmosfera

Há duas condições-chave requeridas para o emprego de SVE. A primeira, é que o solo deve conter uma fase gasosa, através da qual o ar conta- minado irá passar. Esta condição geralmente limita o emprego da SVE na "zona vadosa" (o mesmo que zona não-saturada). Em alguns casos, para melhorar a eficiência dessa técnica, a água subterrânea é bombeada para abaix (N.A.) é, consequeno para a a (N.A.) e, consequentemente, aumentar a área da zona não-saturada, permitindo a aplicação da SVE em áreas classificadas anteriormente como "zon saturada” (zona que pode ser constituída por diferentes níveis ou camadas de solo ou formações rochosas, onde todos os espaços porosos ou faturas existentes estão completamente preenchidos po água. O limite superior dessa zona é designado como o nível freático). A segunda condição, é que os contaminantes devem ser capazes de se transfe( para a fase gasosa, sob a aplicação de vácuo. Este requerimento limita a SVE ao tratamento de compostos voláteis ou semivoláteis, que constituem maior parte dos contaminantes orgânicos de interesse, como os BTEX.

Em suma, no tocante às extrações dos contaminantes por SVE, duas técnicas são utilizadas: uma denominada "vertical" e outra "horizontal". No primeiro caso, os gases são extraídos a partir de pontos específicos construídos (perfurados) sobre a pluma de contaminão. Normados) sobre a pluna de contaninação. Normalmente, o processo é eficiente en profundidades maiores que um metro abaixo da superficie do solo. A segunda técnica, extração horizontal, na maioria da vezes, dependendo da geometria da pluma de contaminação, na maioria das vezes, é instalada en conjunto com a vertical, cuja finalidade é melhorar a eficiência da extração e evitar que os gases contaminantes sejam lançados na atmosfera, antes de tratamento adequado. Os poços de extração de vapor devem ser dispostos de forma que as suas teste piloto) se interceptem e devem ser adequadamente projetados e instalados, para evitar zonas potenciais de estagnação (áreas impactadas ond o ar não é removido pelos poços de extração).

A técnica SVE é aplicada somente para os compostos orgânicos voláteis que apresentam o valor da constante de Henry maior que 0,01 ou a pressão de vapor maior que $0,5 \mathrm{~mm}$ de $\mathrm{Hg}$. Outros fatores, como a umidade e a quantidade de matéria orgânica, afetam consideravelmente permeabilidade do solo e, por consequência, di- minuem a eficiência do sistema de extração. fato de o processo envolver fluxo contínuo de no solo ocasiona, como vantagem, a possibilidade de promover e estimular a biodegradaça in-situ dos compostos no local. A limitação do sistem de SVE é que ele se baseia fundamentalmente na aplicação de fluxos de ar, o que o colicion três fator duxos de ar, o que o condiciona en três facos específicos: volatilidade do contaminante; ausência de ar em ambientes saturados con água e permeabilidade do solo. Normalmente, a SVE não irá funcionar bem em solos de baixa permeabilidade, como aqueles siltosos e argilosos com baixa porosidade, ou em camadas muito saturadas, como a franja capilar ou logo abaixo do nível d’água. En vácuo aplicado com bombas especiais mostrou-se efetiva em alguns solos de baixa persinlidade (CETESB, 2004). Mesmo assim, a maior desvantas processos processos não são de caráter destrutivo e, sim, de transferência de massa, que apenas promovem transferência dos contaminantes de um local para outro, sem que haja a destruição dos mesmos (DiGiulio \& Varadhan, 2001; EPA, 2004c).

\section{BIORREMEDIAÇÃO DE SOLOS}

A biorremediação envolve a utilização de microorganismos, de ocorrência natural (nativos) ou cultivados, para degradar ou imobilizar contaminantes em águas subterrâneas e em solos. Neste caso, geralmente, os microorganismos utilizados são bactérias, fungos filamentosos e leveduras. Destes, as bactérias são as mais empregadas e, por conseguinte, são consideradas como o elemento principal em trabalhos que envolvem a biodegradação de contaminantes. São definidas como qualquer classe de microorganismos unicelulares, geralmente agregados em colônias, que vivem em compartimentos ambientais diversos. São importantes, em função de seus efeitos bioquímicos e por destruírem ou transformarem os contaminantes potencialmente perigosos em compostos menos danosos ao ser humano e ao meio ambien (NRC, 1993). 
No que diz respeito aos tipos de utilização da técnica, quanto ao local de tratamento, a biorremediação in-situ é a mais empregada no mundo. Porém, independente do local de aplicação, a biorremediação, assim como as demais técnicas químicas de degradação, tem como objetivo principal a mineralização completa dos contminantes, ou seja, transformálos em produtos com pouca ou nentura orgânicas, das quais se obtêm nutrientes e energia. Sendo que, para que isso ocorra, os microorganismo

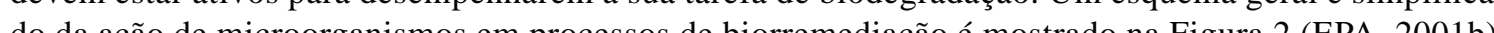
do da ação de microorganismos em processos de biorremediação é mostrado na Figura 2 (EPA, 2001b).

\section{Legenda:}

\section{1- Microorganismo}

2- Contaminante (como petróleo ou outro composto orgânico)

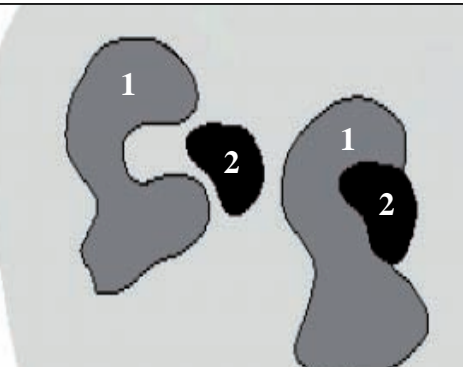

Microorganismo

metaboliza o

contaminante

orgânico
Microorganismo digere o

contaminante e o converte

em água $\left(\mathrm{H}_{2} \mathrm{O}\right)$

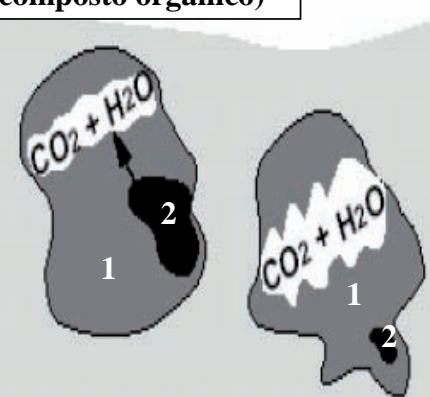

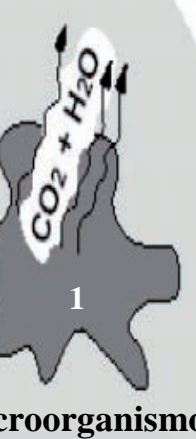

Microorganismo

\section{local de tratamento}

Modificado de EPA

Figura 2. Esquema simplificado da ação de microorganismos em processos de biorremediação (EPA, 2001b)

Genericamente, os microorganismos nativos da subsuperfície podem desenvolver a capacidade de degradar contaminantes após longo período de exposição. Normalmente, estes seres microscópicos se adaptam em baixas concentrações de contaminantes e se localizam nas regiões externas à pluma de contaminação e, muito dificilmente, estarão presentes na fase livre (fase dificica s̃antica con são metabolizados por fermentação, respiração ou co-metabolismo (CETESB, 2004). Portanto, o processo de biorremediação pode ser aeróbico ou anaeróbico, requerendo oxigênio ou hidrogênio, respectivamente. Na maioria dos locais, a subsuperfície é carente dessas espécies (oxigênio ou hidrogênio), o que impede os microorganismos de se reproduzirem e degradarem completamente

contaminante alvo. Além desse dois processos, a biorremediação também pode ocorrer de forma co-metabólica (Vidali, 2001)

Na "biorremediação aeróbica", que reque um meio oxidante, o oxigênio atua como receptor de elétrons e os contaminantes são utilizados pelos microorganismos como fontes de carbono (do-

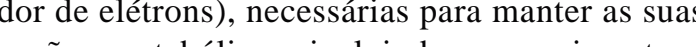
a as cumprem essa função como doadores de elétrons, caso haja receptores suficientes (oxigênio dissolvido) para que a reação ocorra. Quando o oxigênio é totalmente consumido, os microorganismos passam a utilizar outros receptores naturais de elétrons disponíveis no solo, sendo que esse consumo ocorre na seguinte ordem de preferência: nitrato (reação de desnitrificação), manganês, ferro, sulfato e dióxido de carbono, sendo este, convertido em ácidos orgânicos para gerar o metano (Aelion \& Bradley, 1991)

A "biorremediação anaeróbica", que reque um meio redutor, ocorre pela ação de espécies doadoras de elétrons, responsáveis pela degradação, principalmente, dos poluentes halogênicos. Trata-se do fenômeno pelo qual os microorganismos, ao metabolizarem fontes alternativas de carbono (que não sejam os contaminantes de interesse), liberam compostos inorgânicos hidrogenados, hidretos $\left(\mathrm{H}^{-}\right)$, que reagem com as moléculas do contaminante e substituem um átomo de cloro (hidrogenólise) ou removem simultaneamente dois átomos de cloro adjacentes onignando una dois átomos de clono racentes originando uma ligação dupla entre os átonos de carbono. A bioremediação anaeróbica in-situ é ideal para ser utilizada em locais contaminados por compostos organoclorados, como o percloroetileno (PCE), uma vez que a fonte de carbono estimula nas bactérias a reação denominada halorespiração ou haloeliminação. Embora esse princípio, também denominado de descloração redutiva, seja aparentemente simples, a dificuldade da técnica está em criar um modelo ideal de fonte de carbono para un deterino microorganismo. Esta fonte um deterniado mite carbono deve conter compostos que sejam preferencialmente e facilmente metabolizados pelo microorganismos na presença dos contaminantes (Acton \& Barker, 1992). Apesar do tratamento anaeróbico ser menos comum que o aeróbico, existe atualmente uma tendência de se promover biorremediação anaeróbica, utilizando como fontes de carbono, melaço de cana, ácido lático, proteínas do leite e metanol. Considerando o melaço de cana (caso incipiente brasileiro, subproduto da de cana (caso instria indústria sucroalcooleira), é importante ressaltar necessidade de estudos mais avançados e detalhados, envolvendo, principalmente, a ocorrência de diferentes tipos de fermentações. Normalmente, têm-se observado que determinados processos de fermentações podem aumentar consideravelmente os riscos operacionais. Isto ocorre, especialmente, em virtude da metanogênese (etapa final no processo global da degradação anaeróbica de compostos orgânicos, efetuada pelas Archaebacterias metanogênicas, tendo como subprodutos o metano e o dióxido de carbono), que pode resultar em alguns inconvenientes, como alterações do potencial redox (Eh) da matriz estudada, o que pode provocar a solubilização indesejável de metais consequentemente, a contaminação do local por constas espécies (Nakagawa \& Andréa do loc).

A "biorremediação co-metabólica” é aque-

la na qual a degradação ocorre pela ação de enzimas produzidas por microorganismos para outros fins. É uma técnica praticamente idêntica às anteriores, sendo que, do ponto de vista bioquímico, rege o princípio das reações de óxido-redução. No caso específico do co-metabolismo, caso não haja o substrato principal, ou seja, fontes preferenciais de carbono, a degradação mediada pelos microorganismos não ocorre para um dado componente, "cofinido como "contaminante co-metabolizado". Por outro lado, neste caso específico, na presença de uma fonte de carbono, a metabolizaça do substrato prín de a ur pra resse (Garnier et al., 2000).

Não obstante, em poucos casos as condições naturais do local contaminado fornecem todas as substâncias essenciais, em quantidades suficientes, para que a biorremediação possa ocorrer sem a intervenção humana. Esse processo natura também é conhecido como "biorremediação intrínseca" e é utilizada, com sucesso, em alguns trabalhos (Borole et al. 1997; Chen et al., 2006; Troquest et al., 2003). Todavia, mesmo quando o meio é totalmente acondicionado ao cultivo dos microorganismos, a biodegradação pode ser afetada, principalmente, devido à capacidade intrínseca de cada microorganismo de metabolizar uma substância qualquer. Por exemplo, de acordo com Embar et al. (2006), alguns microorganismos sobrevivem em condições ambientais extremamente adversas. Adicionalmente, pesquisas comprovam que diferentes microorganismos podem degradar diferentes substâncias, dentre estas, substâncias recalcitrantes, como os hidrocarbonetos de petróleo. Em alguns casos, certos microorganismo são mais especializados em degradarem contaminantes específicos. Por exemplo, para uma mesma classe de substâncias, como os compostos organoclorados, alguns microorganismos podem degradar contaminantes como o dicloroetano e cloreto de vinila porém, no mesmo local não conseguem degradar o tricloroetano. Contudo, pes- 
quisas sugerem que devido à elevada diversidade de compostos em solos contaminados por petróleo e derivados, estudos preliminares à biorremediação são de suma importância para o tratamento dessas matrizes ambientais (Embar et al., 2006). Salienta-se que, a princípio, o fator crítico para definir se a biorremediação é a técnica mais apropriada para o tratamento do local contaminado é a biodegradabilidade do contaminante. Por isso, o estudo detalhado de cada parâmetro que afeta a biodegradação deve ser feito cautelosamente pelos responsáveis do projeto de remediação. O item a seguir descreve a influência desses fatores na biorremediação

Fatores que influenciam a biodegradabilidade dos contaminantes e a problemática da contaminação de solos por petróle

Embora vários contaminantes podem ser metabolizados por microorganismos, alguns são mais facilmente biodegradados do que outros. No caso dos hidrocarbonetos de petróleo, por exemplo, muitas áreas contaminadas possuem uma mistura complexa de compostos orgânicos, sendo que a maioria destas substâncias, certamente, não é metabolizada na mesma velocidade. Em vez disso, as taxas de degradação dos diversos compostos que são metabolizados são diferentes e dependentes de vários fatores. Em especial, a velocidule de degradrão do va concentraça do contaminante e da quantidade de espécies catalisadoras, como as enzimas geradas on-site pelos microorganismos. Nesse contexto, a quantidade de catalisador presente, de certa forma, representa o número de microorganismos hábeis em metabolizar o contaminante, bem como a quantidade de enzimas produzidas por cada célula. Então, qualquer fator que afeta a concentração do contaminante, o número de microorganismos presentes ou a quantidade de enzimas específicas, pode aumentar ou diminuir a velocidade da biodegradação do contaminante.

Em suma, as medidas corretivas a serem adotadas em quaisquer projetos que envol biorremediação dependem de vários fatores, dentre eles, pode-se citar: A) os tipos e as quantidades dos microorganismos e B) as condições físicas e químicas do sítio contaminado (como pH, umidade, temperatura, salinidade, teor de oxigênio e quantidade de nutrientes). Os nutrientes, que geralmente são representados por nitrogênio, fósgerantionsio (

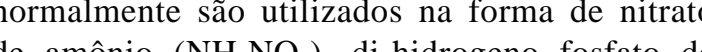
de amônio $\left(\mathrm{NH}_{4} \mathrm{NO}_{3}\right)$, di-hidrogeno fosfato de potássio $\left(\mathrm{KH}_{2} \mathrm{PO}_{4}\right)$ e nitrato de potássio $\left(\mathrm{KNO}_{3}\right)$, respectivamente (Betancur-Galvis et al., 2006) Além das condições citadas, é de extrema importância o conhecimento prévio do teor de matéria orgânica, o qual pode ser expresso pela quantidade de carbono orgânico total no meio.

Adicionalmente, Hutchinson et al. (2003) constataram que o fator principal que influencia na biorremediação de solos contaminados por hidrocarbonetos de petróleo é a atividade microbiológica. Neste caso, Alexander (1977) discutiu, em detalhes, os efeitos desses fatores sobre os microorganismos. Para estes pesquisadores, a atividade a população microbial estão fortemente associadas com os conteúdos de água e de nutriente nos solos, com as espécies de plantas e com os tipos de contaminantes. Além disso, a atividade microbiológica é afetada, sobretudo, pelo valor mo $\mathrm{pH}$ (Figura 3) e pela temperatura (Figura 4) dos solos (Tate, 1995).

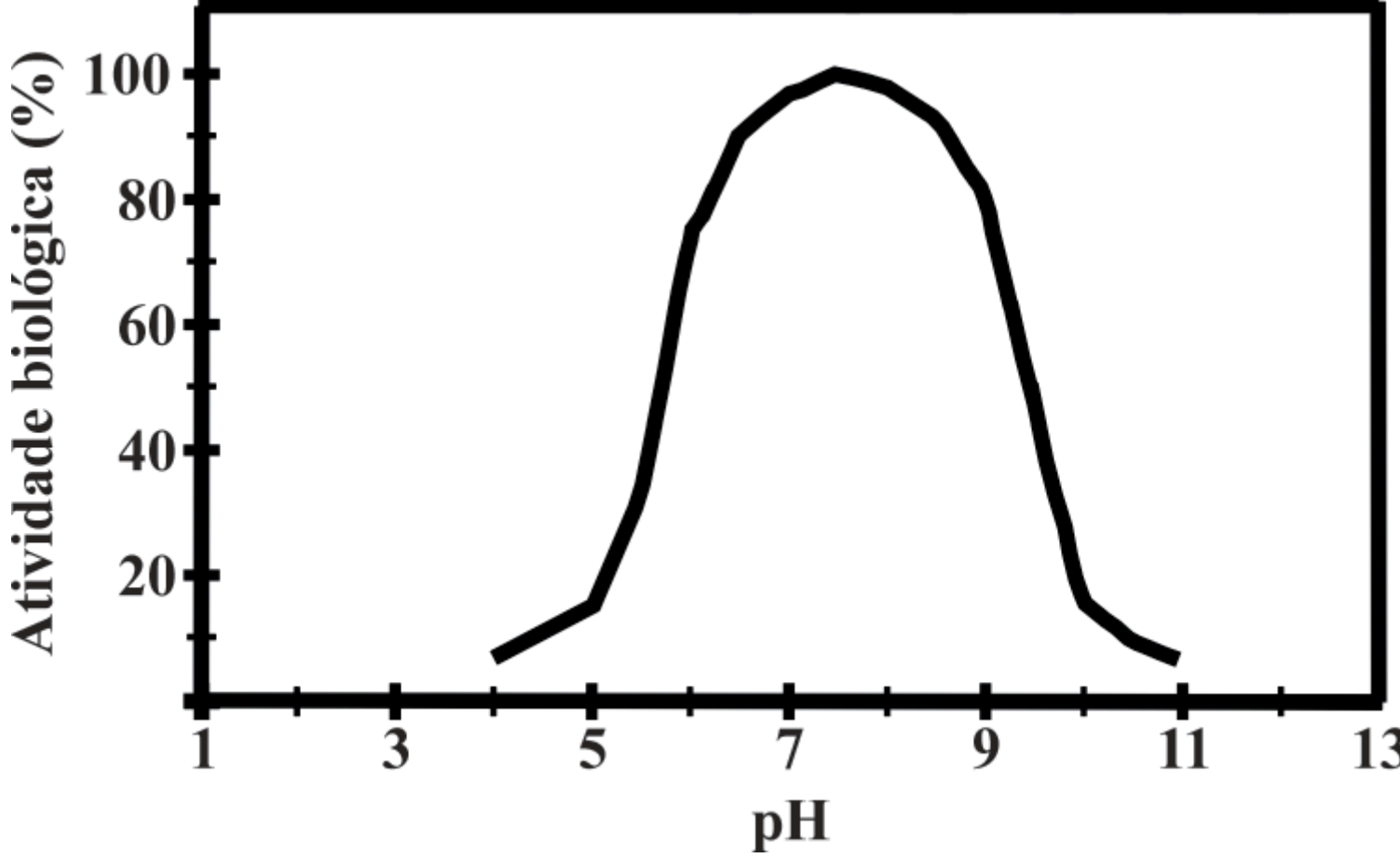

Figura 3. Variação da atividade biológica com a mudança do pH dos solos (modificado de Tate, 1995)

No tocante ao valor do $\mathrm{pH}$, como mostra a Figura 3, observa-se que a faixa ideal de $\mathrm{pH}$ para que os microorganismos tenham atividade máxima é entre 6,5 e 8,5. De modo similar, Vidal (2001) também sugere que o valor do $\mathrm{pH}$ do meio reacional deva ser mantido próximo da neutralidade, no qual há o predomínio de bactérias e de fungos no local contaminado. Por outro lado, quando há diminuição do valor do $\mathrm{pH}$, por exemplo, en função dos subprodutos ácidos gerados durante a biorremediação, sugere-se que se faça imediatamente a correção do pH do solo, caso contrário, a eficiência do processo poderá ser diminuíd consideravelmente Normalmente, essa correção eita por meio de “calagem”, processo através do qual se aplica calcário ao solo, objetivando neutralizar a acidez e, então, propiciar condições para o desenvolvimento de plantas e de microorganismos. Salienta-se, porém, que nos solos ácidos o desenvolvimento dos microorganismos é bastante

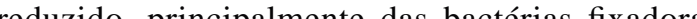

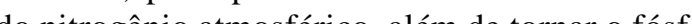

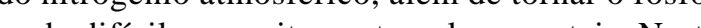
ro de dificil aprove a biodro peros vegetas. Nesta situação, embora a biodegradação de hidrocar- bonetos de petróleo seja, na maioria das vezes, realizada por bactérias, pesquisas mostram que a utilização de fungos é uma opção considerad bastante viável. Esses microorganismos têm sido mais eficientes que as bactérias para agirem en condições ambientais adversas, como em valores extremos de $\mathrm{pH}$ (menor que 5 e maior que 10), em concentrações limitadas de nutrientes e em solos 


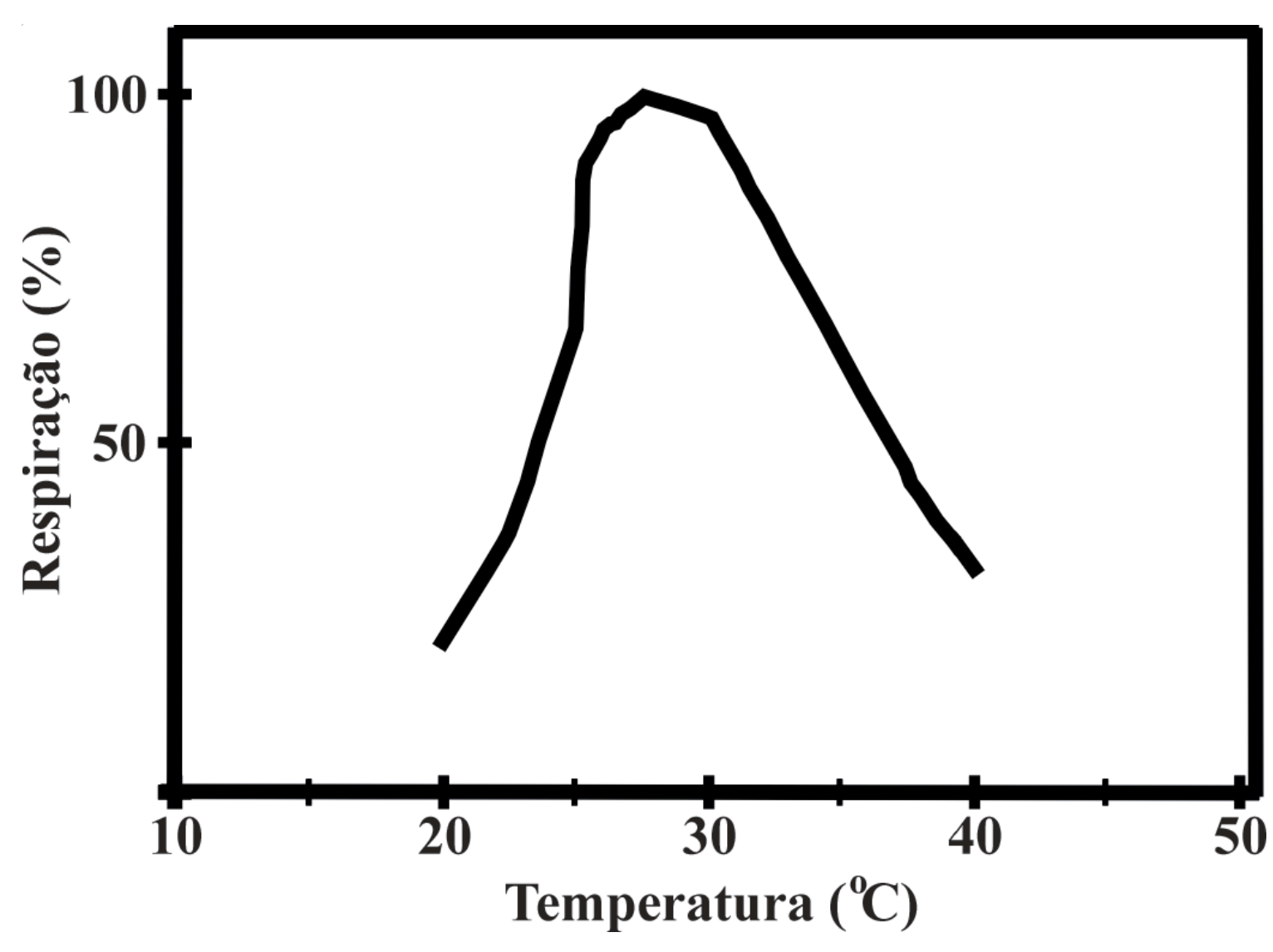

Figura 4. Resposta típica de uma população de bactérias mesofílicas em função da variação da temperatura dos solos (modificado de Tate, 1995)

A análise da Figura 4 mostra que a faixa de temperatura ideal para os microorganismos metabolizarem os contaminantes com eficiência ótima está entre 25 e $30^{\circ} \mathrm{C}$, na qual se encontra a temperá entre 25 e 3 peratura média da $\mathrm{C}$ aior parte dos solos do Brasil contendo áreas degradadas por contaminação de hidrocarbonetos do petróleo (Tate, 1995). Analogamente, estudos realizados pela EPA (1995) constatam que a atividade microbiana é bastante comprometida em temperaturas abaixo de $10^{\circ} \mathrm{C}$ e acima de $45^{\circ} \mathrm{C}$. Esta é uma excelente característica para a utilização de biorremediação em solos tipicamente brasileiros e, portanto, reforça a probabilidade da implantação dessa técnica em números maiores de locais contaminas. Além disso, veriffa-se que a tenperatua do solo varia diariamente nas proximidades da superfície, em solos com baixa densidade de cobertura vegetal.

Abaixo de $50 \mathrm{~cm}$, a variação da temperatura dos solos é pouco significativa.

Por outro lado, a presença da vegetação sobre a área contaminada também afeta muitos atributos físicos dos solos, incluindo estrutura, porosidade, condutividade hidráulica e taxa de infiltração. Esses atributos, em geral, influenciam positivamente a atividade microbiológica por regular o transporte requerido de água e de nutrientes através do perfil dos solos e por controlar a aeração da zona vadosa. Além do mais, a biorremediação de hidrocarbonetos de petróleo é assistida por microorganismos, que, em geral, dependem fortemente das quantidades de umidade e de exigennio adequas. As propriedades físicas de As popriededes fisicas do solos influenciam o transporte de ambas espécies, oxigênio e água. Nesse caso, para a biorremediação de solos, os conteúdos de água entre 50 e $80 \%$ da capacidade e o teor de $\mathrm{O}_{2}$ dissolvido maior que
$1 \mathrm{mg} \mathrm{L}^{-1}$, geralmente, são ótimos para a atividade microbiológica (Morgan \& Watkinson 1989).

Portanto, conforme aventado na presente

revisão, observa-se que os solos possuem, naturisante, diversos microos comismos com dades metálicas vaiadas e que são capazes de dades metabólicas variadas e que são capazes de degradar eficientemente diferentes contaminantes, como o petróleo e seus derivados. Contudo, em alguns casos, a contaminação de solos por estas substâncias tem se tornado uma problemática mundial, principalmente, devido à dificuldade de reabilitar a área contaminada. Estes problemas têm ocorrido, pois uma das principais dificuldades envolvendo a descontaminação dessas matrizes está relacionada, entre outros fatores, à presença de materiais a gilominerais. Estes algilomineras, de materiais agilominerais. Estes argilominerais, quando presentes em quantidades elevadas no solo contaminado, podem reduzir consideravelmente eficiência do processo de biorremediação. Sabe-se que os solos argilosos, de modo geral, apresentam baixa permeabilidade, o que pode comprometer significativamente tanto a difusão de oxigênio, que é o elemento fundamental ao processo aeróbico de degradação, bem como a incorporação de nutrientes. É evidente que a estrutura dos solos também exerce influências significativas sobre as característica físico-qúmicas. Dependendo d a cstutura,

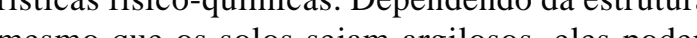
mesno que os sols sejan arglosos, eles podem ter permeabilidades elevadas. Os latossolos argilosos, por exemplo, que ocupam extensas áreas no Brasil, apresentam comumente estrutura granula e, desta forma, elevada permeabilidade.

Além da presença de argilominerais, muitos compostos orgânicos apresentam como características físico-químicas, baixa solubilidade em água, elevada afinidade pela matéria orgânica do solo, como os ácidos húmico e fúlvico e, consesolo, como os ádos hic quentes da fase solida para a ausos. Sendo assim, luentes da fase sólida para a aquosa. Sendo assim, devido principalmente às características hidrofóbicas, esses contaminantes tendem a se adsorverem nos colóides do solo dificultando a ação de microorganismos e, por conseguinte, inviabilizando a técnica de biorremediação. Portanto, outra limitação da biorremediação surge devido à baixa disponibilidade de contaminantes orgânicos, como os HPA e outros hidrocarbonetos de petróleos. Schwarzenbach et al. (1993) presenciaram e relataram sobre estas e outras propriedades para

Nesse contexto, a utilização de um agente tensoativo pode minimizar essas dificuldades aumentar a ficiência da biorremediaço, baja vista que os problemas relativos à baixa soly em água, elevada adsorção e baixa tralu filidade dos hidrocabonetos para a fase aquosa s̃o minimizados. De acoso com Ou (2000), de fa mimizados. De acordo com Ou (2000), de fato, maior eficiência na biorremediação de solos contaminados com hidrocarbonetos de petróleo pode ser alcançada empregando-se surfactantes. Estes compostos diminuem a tensão superficial entre fase aquosa (na qual normalmente ocorre a degradação do contaminante) e a fase orgânica (na qual o contaminante se encontra inicialmente presente), favorecem a dessorção e, consequentenente, aumentam a solubilidade dos contrato surfactantes, como o dodecil sulfato de sódio, sa capazes de cono o dodecil sulfato de sódio, são capazes de enulsificar e aumentar a solubilidade dos contaminantes hidrofóbicos, tornando-os mais

Cos aos microorganismos (CLU-IN, 2006). Contudo, conclui-se que a degradação biológica de compostos orgânicos é alcançada com eficiência somente em condições naturais favoráveis, que proporcionem interações otimizadas entre 0 microorganismo e o solo, entre o microcontaminante, assim como a relacão mútua dos microorganismos entro exemplo, Coulon \& Delille (2006) e Hawrot \& Nowak (2006) inve Dellle (2006) e Hawrot \& Nowak (2006) investigaram que as propriedades físicas, químicas e microbiológicas do solo e as condições climáticas, podem alterar a taxa de biodegradação de poluentes em solos contaminados, por exemplo, com óleo diesel. Neste caso, podem ser empregados nutrientes, como o nitrogênio, fósforo e o potássio, além de procedimentos para a correção de umidade e o controle da aeraça processos de biorremediação. A Figura 5 mostra o esquema típico de um proje envolvendo a aplicação in-situ da biorremediação (EPA, 2003b). 


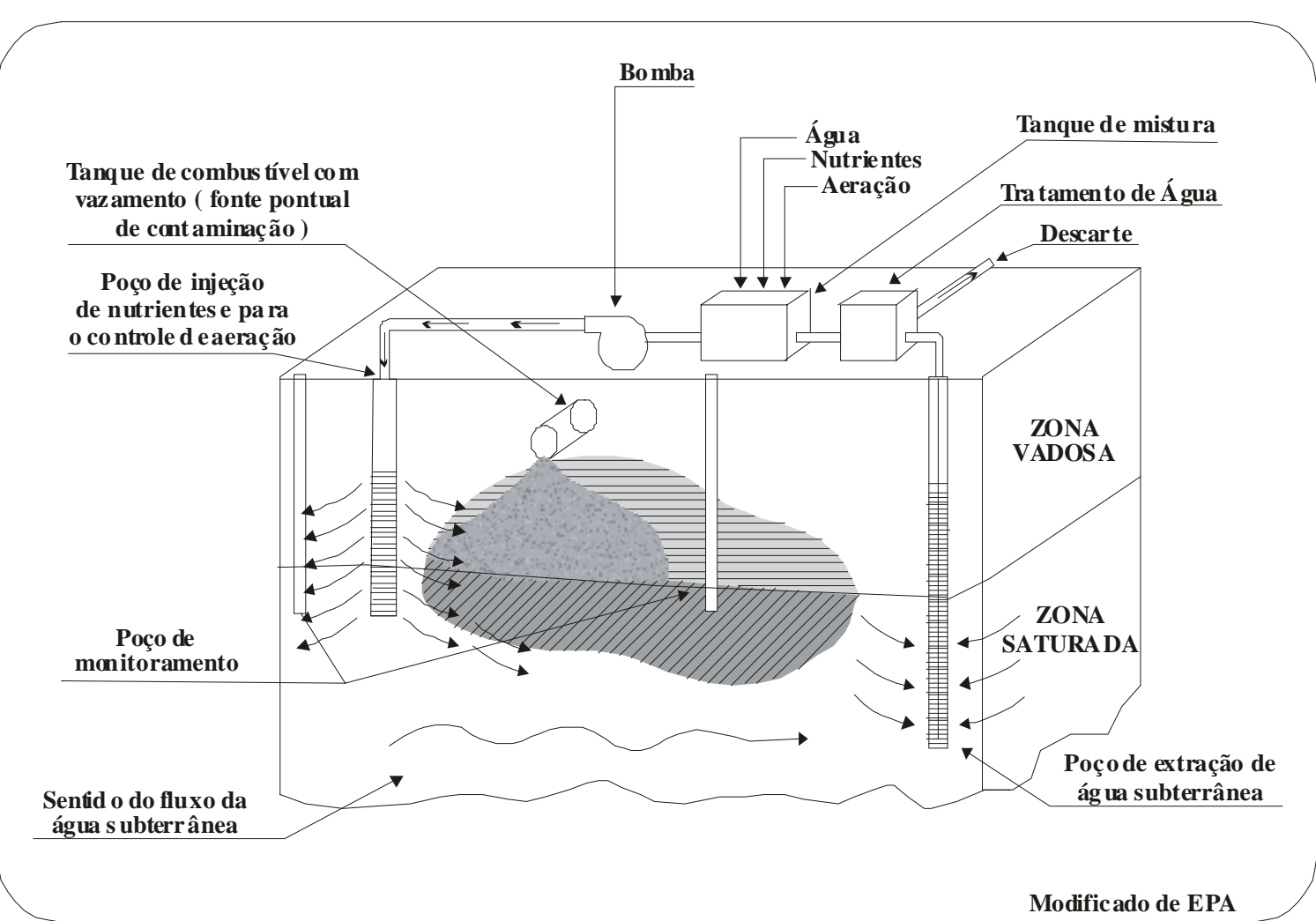

Figura 5. Esquema típico do tratamento de solos e de águas subterrâneas por biorremediação (EPA, 2003b)

\section{Técnicas de utilização da biorremediação} ção)

A técnica denominada de atenuação natu-

Desde os meados dos anos 80 do século $\mathrm{XX}$, as estratégias de biorremediação têm sido adotadas como uma maneira eficaz e de custo baixo para o tratamento de solos contaminados com petróleo (Delfino \& Miles, 1985; Tsao et al., 1998; van der Hoek et al., 1989). As diferentes estratégias de biorremediação, em geral visam aumentar a populac̃o microbiant ciando condições ambieptrs favoravis ao seu desenvolvim bientais favoráneis ao seu deranglvinento (Silva et al., 2004). A seguir, serão apresentadas duas das técnicas principais de biorremediação in-situ, a primeira é a "atenuação natural acelerada", também conhecida por "bioestimulação" e, a segunda, trata-se da "bioaumentação". Em seguida, será descrita uma das técnicas mais utilizadas para o tratamento ex-situ de solos contaminados, que é a biorremediação por "biopilhas".

Atenuação natural acelerada (bioestimularal acelerada (ANA), diferente da ANM (técnica descrita anteriormente), é uma opção de biorremediação in-situ na qual se busca, especialmente, instigar o crescimento da população microbiana nativa. Isto ocorre, fundamentalmente, pelo condicionamento do hábitat natural desses microorganismos. Portanto, na ANA, a idéia fundamenacelerar o processo de atenuação natural, estimuando, sobretudo, o desenvolvimento dos microorganismos autóctones (indísenos). Ressalta-se qui, que esses microorgnismos, para sere

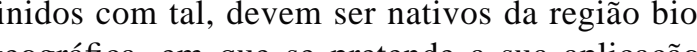
geográfica, em que se pretende a sua aplicação, participando de funções reprodutivas, de ciclo de nutrientes e de fluxos de energia (EPA, 2004d).

Para que esta técnica de biorremediação seja utilizada de forma eficiente, o primeiro requisito a ser atendido é a necessidade dos microor- ganismos indígenos apresentarem a capacidade de descontaminar o poluente alvo. A ANA, quando utilizada de forma controlada, é capaz de acelera o processo natural e diminuir o tempo de biorremediação do local, sendo que para isto, normalmente adiciona-s oxigenio, hidrogenio e nuignes. A adiça de nuigenio, hidrogenio e nutrientes. A adção de tais pente a otimização das condições ambienas atividades metabólicas de microorganismos, com o consequente aumento da velocidade e da porcentagem de biodegradação. Neste contexto, a bioestimulação pode oferecer custo mais baixo em relação às demais técnicas de biorremediação (EPA, 2004d).

\section{Bioaumentação}

A bioaumentação, apesar de ser uma técnica relativamente recente e ainda em fase de desenvolvimento, encontra-se bem documentada na literatura. Resumidamente, ela é caracterizada pelo aumento da microbiota nativa através da inoculação de microorganismos exógenos (alóctones) Estes microorganismos são pertencentes à espécie não nativa de determinada região biogeográfica, introduzidos em um ecossistena, podendo persisir e até reproduir-se por un tempo, paticipando ou não de interações e de transformações ecológicas (EPA, 2004d)

A utilização da bioaumentação em solos, tal é condicionar o local contaminado, de modo a a qui, que esses microorganismos, para serem de- basicamente, é justificada pela necessidade 1) de uma biodegradação rápida do composto poluente e 2) da redução do período de adaptação que normalmente antecede o processo de degradação pelos microorganismos autóctones. O emprego desta técnica depende, primeiramente, da con

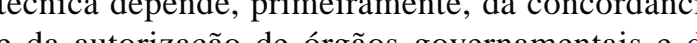
e da autorização de órgãos govennamentais e de agências de fiscalização ambiental, como a Comestratégia de biorremediação depende de vários fatores, dentre os quais, os tipos de microorganismos utilizados e a área de aplicação.

Nessa conjuntura, um ressalva deve se feita no que diz respeito à utilização da bioaumentação em solos tipicamente brasileiros. Até junho de 2007, no Brasil, era proibida a utilizapanhia de Tecnologia de Saneamento Ambiental (CETESB). A aprovação da bioaumentação como lizações. No entanto, em 22 de junho de 2007, CETESB, através da Decisão de Diretoria (DD) $n^{0}$ 103/2007/C/E (essa DD possui caráter normativo), publicou a seguinte informação “ “. A utilização de microorganismos alóctones nos sistemas de remediuca a dever seguir as nor nos sistemas CETESB as legais perin as normas técnicas CETESB e as legais pertinentes..." (CETESB. 2007a). Assim sendo, após essa data, a utilização da bioaumentação passou a ser permitida no Brasil, mais especificamente no Estado de São Paulo, porém, desde que sejam seguidas as normas pertinentes, explicitadas no referido documento. Dentre as normas a serem seguidas, destaca-se a norma técnica da CETESB n ${ }^{\circ}$ L1.022, de junho de 2007, que trata sobre 0 uso de produtos biotecnológicos, constituídos de microorganismos,

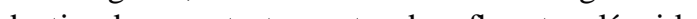

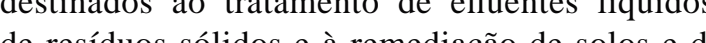
ediação de solos e de guas (CETESB, 2007b)

Atualmente, muitos produtos têm sido lançados no mercado mundial com o intuito de auxiliar no tratamento de solos contaminados por petróleo. Alguns produtos comerciais apresentam, em sua composição, microorganismos exógenos que são utilizados com o objetivo de induzir a bioaumentação do solo a ser tratado. A fim de melhorar as condicones de biodegradac̃o do conmalhor as cond cos de biodega determinados produtos também apreseñ su for such f̧acho micronutrientes, enzimas de ação externa e surfactantes que facilitam e estimulam ação microbiana sobre os poluentes. Neste caso, as enzimas de ação externa atuam favorecendo a oxidação dos compostos de difícil degradação em compostos de fácil assimilação pelos microorganismos. Existem, porém, dois tipos básicos de enzimas que na presença de $\mathrm{O}_{\text {a atuam na oxidação }}$ de hidrocarbonetos: as "monoxigenas", que atuam sobre os n-alcanos; e as "dioxigenas", que atuam sobre os compostos aromáticos e ciclicos. Por outro lado, os surfactantes agem de ciclicos. disponibilizar o petroleo para que este seja mas disponibilizar o petróleo para que este seja mais facilmente degradado pela microbiota (Shuhong et al., 2006)

Inversamente às vantagens apresentadas, em casos nos quais a bioaumentação de solos se mostra ineficiente, o insucesso da introdução de microorganismos poderá estar relacionado con alguns fatores, como a limitação de nutrientes, a 
eliminação por predatismo de microorganismos introduzidos, a concentração de poluente orgânico muito baixa para suportar o desenvolvimento e, até mesmo, aos fatores ambientais desfavoráveis ao crescimento desses microorganismos (Alexander, 1999; Sims et al., 1992). Além disso, o lançamento de microorganismos alóctones pode acarretar em riscos consideráveis ao meio ambiente. Desta maneira, em função dos riscos ambientais associados, por exemplo, ao emprego de produtos biotecnológicos, é de suma importância que tais produtos sejam devidamente avaliados antes de sua aplicação para, então, promover a degradação de poluentes em sistemas de tratamento de resíduos ou em locais contaminados. Este procedimento deve ser rea utilização como prática segura e eficaz dos pontos de vista ambiental e sanitário.

Segundo a CETESB, os produtos biotecnológicos podem ser constituídos de microorganismos viáveis, metabólitos (como as enzimas) ou, ainda, misturas de microorganismos e metabólitos contendo produtos orgânicos e inorgânicos, atuando como conservantes, estabilizantes, nutrienes, ativadores e outros. A grande preocupação, portanto, é que os microorganismos viáveis presentes no produto acabado podem reproduzir-se, dissemin pre por novos locais e áe disseninar-se por novos locaise até transferir material genético para os microorganismos naturalmente presentes no ambiente. Do mesmo modo, as enzimas podem catalisar reações que interfiram no metabolismo normal de organismos originariamente existentes e, além disso, a introdução de nutrientes e de outros compostos podem provocar o desequilíbrio do ecossistema (CETESB, 2007b).

Apesar de toda essa discussão, a respeito da inserção de microorganismos não-indígenos no solo, Top \& Springat (2003) defendem que no solo, Top \& Springael (2003) defen que 0 uso de microorganismos não modificados normalmente não constitui problema, contrariamente ao que se verifica com os microorganismos geneticamente modificados, cuja utilização requer uma avaliação mais criteriosa. Assim sendo, as técnicas biologicas que envolvem o uso da bioaumentação, isto é, que empregam a adição de microorganismos exógenos, devem ser analisadas criteriosamente devido, principalmente, aos riscos ambientais que a inserção de um microorganismo não nativo ao solo pode gerar. Por esse motivo, as técnicas de biorremediação que aplicam apenas o uso da microbiota nativa podem vir a produzi resultados eficazes e de menor impacto ao meio mbiente (Silva et al., 2004).

\section{Biopilhas}

O tratamento por biopilhas é controlado por processos biológicos ex-situ sob condiçõe aeróbicas. Essa técnica de biorremediação envolve basicamente a disposição do material contaminado em montes denominados de biopilhas. Para o emprego desta técnica, inicialmente o solo é escavado e, em seguida, preparado e colocado

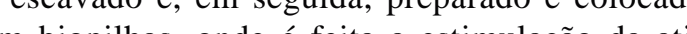
didade nicrobian âtavés de aeção, da adição co solo, com o propósito de promover a biodegradação dos contaminantes de interesse. O esquema característico do sistema de um tratamento por biopilhas é mostrado na Figura 6 (EPA, 2004e).

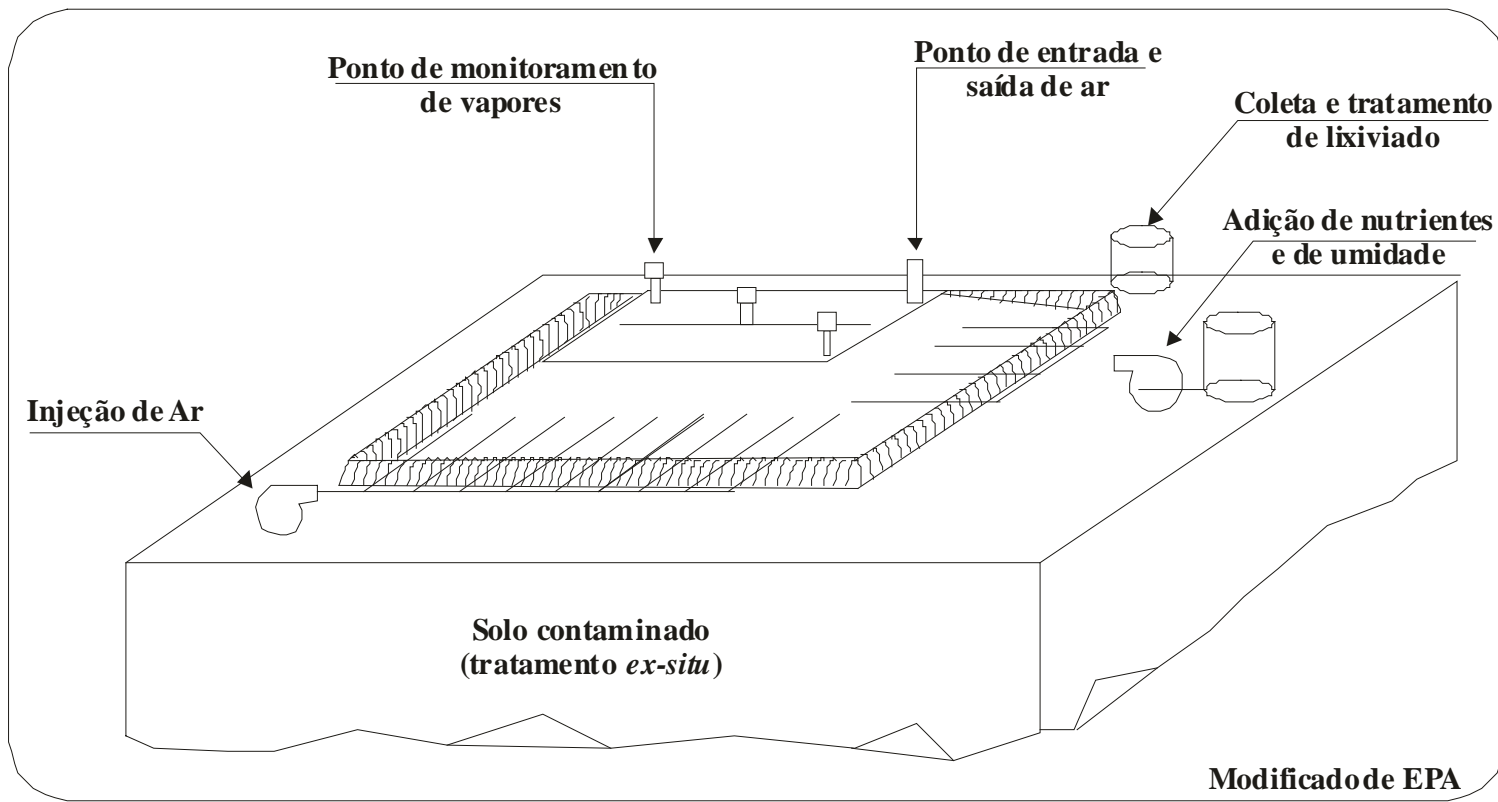

Figura 6. Esquema ilustrativo de um tratamento por biopilha (EPA, 2004e)

As biopilhas são construídas sobre uma base impermeável para reduzir o potencial de migração do lixiviado da camada superficial para a subsuperfície do solo. Além disso, elas são cobertas por uma membrana, também impermeável, para prevenir a liberação de contaminantes volàteis e semivoláteis do solo para a atmosfera, bem como para proteger o solo de intempéries naturais, como ventos e chuvas (USAEC, 2003a). Os materiais a serem tratados devem ser submetidos a um estudo prévio, para a comprovação da tratabilidade, mediante a palizaça de testes físico-químicos (aímicos e de ensaios biológicos e posterior otimização das condicionantes en laboratónio. O propósito destes estudos é avaliar o tipo e a concentração do poluentes, a presença de possíveis inibidores da biodegradação, a estrutura do material, os teores ótimos de umidade, de nutrientes e de oxigênio, emperatura e os demais fatores que influenciam no processo (EPA, 2004e).

Esta técnica de biorremediação apresenta como principal vantagem a possibilidade de maior controle das condiç̃ões físicas, biológicas e químicas da matriz con

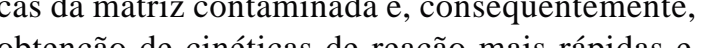
redução do tempo de degradação do contaminant quando comparado ao processo de atenuação natural. Particularmente, quando as condicionantes do meio são bem controladas, as biopilhas têm sido bastante eficientes na redução da concentração de compostos derivados de petróleo presentes em solos. A maior limitação desta técnica está relacionada à remoção do solo contaminado, tendo em vista que o processo de tratamento ocorre no modo ex-situ. Neste caso, apesar de possibilitar a eliminação dos principais focos de contaminação na zona não-saturada, essa prática deve ser realizada com cautela, pois pode propiciar a intensifcação do risco às vias de exposição humana, como a ina ça de vapores e de materis particulas contaminados, cuja causa é advinda da transferência do passivo de um compartimento ambiental para outro (durante a escavação, o armazenamento, o transporte e a redisposição dos solos contaminados). O passivo ambiental dessa área é composto não apenas do material que está sobre o solo e pode ser contabilizado facilmente, mas também de todo o contaminante que possivelmente foi lixiviado da superfície do solo e pode estar no aquifero ou em bolsões localizados na subsuperfície. Além disso, a remoção e a redisposição de solos, dependendo da quantidade do material removido, 
podem se tornar a alternativa mais onerosa dentre também poderão se tornar contaminados. Por as técnicas de remediação, pois, além dos custos relacionados com a remoção propriamente, devem ser considerados os custos do transporte, do tratamento e da disposição final do solo tratado, além de outras exigências, como o treinamento de pessoal. Essa prática também apresenta a desvantagem de que a remoção do solo deve ser realizada com todos os cuidados para que não ocorra a propagação da contaminação para outros meios, inicialmente os não afetados, como o ar e as águas, ao exemplo do que ocorreria durante a remoção de solos contaminados com substâncias voláteis (EPA, 2004e)

Assim sendo, o transporte e o tratameno off-site dos solos por biopilhas possibilitam a transferência do problema para outros locais que

Tabela 1. Vantagens e limitações da biorremediação de solos

$$
\text { VANTAGENS }
$$

LIMITAÇÕES

A aplicação envolve o uso de equipamentos de fácil obtenção, instalação e operação. Podem ser requeridos monitoramento contínuo por biorremediação.

Em atividades in-situ, a biorremediação gera distúrbios mínimos ao meio ambiente.

A técnica é ineficiente para compostos orgânicos que ficam adsorvidos no solo, tornando-os indisponíveis à biodegradação

Em condições ótimas de operação, apresenta custos É menos eficiente em períodos menores de tempo menores em comparação às técnicas alternativas de em comparação às outras técnicas de remediação, remediação.

Pode ser combinada com outras técnicas, como SVE, para acelerar o processo de descontaminação.

Na maioria dos casos, essa técnica não produz compostos tóxicos, que devem ser dispostos e tratados em outro local.

É muito eficiente na biodegradação de petróleo e Dificuldade de utilização em solos argilosos ou com seus derivados em solos permeáveis.

Ressalta-se que no Brasil, até o momento, apenas alguns estudos foram realizados abordando a temática de biorremediação de solos. Ao contrário, em outros países, como nos Estados Unidos, essa questão é estudada com frequência, tanto no meio acadêmico como no industrial. Por isso, nos últimos anos, a biorremediação de solos tem se tornado tema recorrente de muitos estudos acadêmicos, gerando literatura técnico-científica abundante.

\section{LEGISLAÇÃO AMBIENTAL}

Conforme foi discutido, considerando as contaminações de solos por petróleo e seus de vados, caso os compostos orgânicos orimus desvados, caso os conpostos organicos oniundos dessa contaninação fossem distribuidos em ordem de "toxicidade", "persistência no meio ambiente" e "efeitos carcinogênicos e mutagênicos", os BTEX, HPA e HTP representariam as três classe de compostos mais importantes a serem estudadas. Sendo que, especialmente por esse motivo, estes compostos têm sido frequentemente objetos de discussões nos órgãos governamentais de fiscalização ambiental (VROM, 1994).

De acordo com as legislações ambientais a da Holanda (Dutch $R$ rence Framework STI - Values), a biomentiaça só é recontecida como tal se recuperar o solo iñ cón gralmente, com base no padrão agrícola de fertilidade. O Ministério da Habitação, Planejamento e Meio Ambiente Holandês (VROM) publicou, en atendimento à Lei de Proteção de Solo (Soil Protection Act), os valores das concentrações permi-

Tabela 2. Valores de referência (S), de alerta (T) e de intervenção (I) para solos, segundo a legislação holandesa, considerando-se os teores de argila e de matéria orgânica de 0 \% (CETESB, 2001; VROM, 1994)

\begin{tabular}{cccc}
\hline \multirow{2}{*}{ COMPOSTO } & \multicolumn{3}{c}{ CONCENTRAÇÃO EM PESO SECO (mg kg-1) } \\
& $\mathrm{S}$ & $\mathrm{T}$ & $\mathrm{I}$ \\
\hline Benzeno & 0,01 & 0,11 & 0,20 \\
Tolueno & 0,01 & 13,0 & 26,0 \\
Etilbenzeno & 0,01 & 5,0 & 10,0 \\
Xilenos & 0,01 & 2,5 & 5,0 \\
HPA & 0,2 & 4,1 & 8,0 \\
HTP & 10 & 505 & 1000 \\
\hline
\end{tabular}

No Brasil, mais especificamente no Estado de São Paulo, os valores orientadores para solos são mostrados na Tabela 3. Neste, os valores descritos para os HPA correspondem à soma das concentrações de dez compostos prioritários selecionados pela CETESB (ver a lista dos compostos no rodapé da Tabela 3). Vale ressaltar que, no Brasil, não existe uma legislação especifica para HPA total, bem como para HTP (CETESB, 2005). 
Tabela 3. Valores orientadores para solos no Brasil (CETESB, 2005)

CONCENTRAÇÃO EM PESO SECO (mg kg-1)
COMPOSTO

Valores de
prevenção

prevenção

0,03

Benzeno

Tolueno

Etilbenzeno

Xilenos

HPA*

HTP

0,14

6,2

0,13

12,7
* Soma das concentrações de dez compostos selecionados pela CETESB: antraceno, benzo(a)antraceno, benzo $(k)$ fluoranteno, benzo $(g, h, i)$ perileno, benzo $(a)$ pireno, criseno, dibenzo $(a, h)$ antraceno, fenantreno, indeno(1,2,3-c,d)pireno e naftaleno.

\section{APLICAÇÕES E INOVAÇÕES DA BIORRE-}

\section{MEDIAÇÃO DE SOLOS}

Baseados na descoberta de que os microorganismos endógenos, presentes em areias de praias ou em solos, podem degradar hidrocarbonetos de petróleo nesses locais, desde então, muitas pequisas vên sendo realizadas envolvenui-

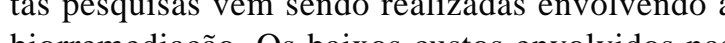
biorrentiç ça. Os baixos custos envolvidos nas transformações bioquímicas in-situ, além da possibilidade de redução ou ate mesmo de eliminação total dos contaminantes, são condições que favorecem a atratividade das técnicas de biorremediação. Esses fatores atualmente têm sido considerados como os principais responsáveis pelas vastas aplicações e inovações surgidas na área de remediação de solos mediada por microorganismos.

A maioria das inovações envolvendo a biorremediação de solos, ao contrário de diversas técnicas ligadas à degradação de compostos orgânicos, não está relacionada com o desenvolvimento de novas técnicas analíticas e de novos equipamentos empregados para o monitoramento ambiental e para a identificação desses compostos. O estado da arte está focado no desenvolvimento de novos reagentes, que têm sido produzidos com o objetivo de serem utilizados in-situ para acelerar e melhorar a eficiência da biorremediação. Além disso, as inovações nessa área também estão direcionadas ao estudo biotecnológico envolvendo a geração de organismos geneticamente modificados, desenvolvidos com o intuito de degradarem contaminantes específicos em diferentes nichos ecológicos (Saul et al., 2005; Sánchez et al., 2006)

No tocante ao desenvolvimento de novos reagentes, cujas utilizações estão voltadas para ação in-situ, podocessos bioquínicos de degraa "Recalizada na Califónnia (EUA), denominada "Regenesis". Esta empresa realiza, entre outras atividades, serviços de consultoria e de remediação ambiental, além de desenvolver e comercializar produtos que aceleram a degradação natural de contaminantes. Um dos produtos desta empresa é o Oxygen Release Compound $\left(\mathrm{ORC}^{\circledR}\right)$, que vem sendo amplamente empregado em inúmeros casos reais, sendo que existe un

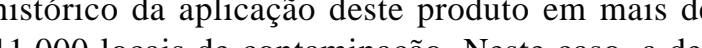
1.000 locais de contaminação. Neste caso, a deutilizando-se o ORC ${ }^{\circledast}$, consiste, basicamente, na quisas mostram que estes reagentes, dependendo das condições do local, quando hidratados, podem liberar oxigênio molecular de maneira lenta e em histórico da aplicacão deste produto em miste um gradação aeróbica de hidrocarbonetos de petróleo adição de peróxido de magnésio e de fosfato. Pes- concentrações controladas durante um período de até 12 meses (Bastiaens et al., 2003; Colvin, 2005; Fukada \& Takagi, 2003; Koennigsberg \& Willett, 2005; Reed, 2004; Wynm, 2003). A equação química dessa reação é:

$$
\mathrm{MgO}_{2}+\mathrm{H}_{2} \mathrm{O} \rightarrow 1 / 2 \mathrm{O}_{2}+\mathrm{Mg}(\mathrm{OH})_{2}
$$

Ressalta-se que, no Brasil, a CETESB já aprovou a utilização dos reagentes produzidos pela Regenesis, em casos de biorremediação de solos. O método mais recente e recomendado pel EPA para a quantificação dos compostos do petróleo e derivados é o Método 8260C. Assim como neste método, a maioria das determinações de BTEX, HPA e HTP, descrita por outros métodos, é realizada empregando técnicas analíticas baseadas em cromatografia gasosa. Para a quantificação destes compostos, os detectores mais utilizados são o por ionizaça os em chama e o espectrôndos são o por inização ento de dores de gases, tanbêm são comumnente utilizados para o monitoramento destes compostos. Geralmente, esses equipamentos operam com detectores de infravermelho (EPA, 2006)

De acordo com Maila \& Cloete (2005), as atividades biológicas dos solos são vitais para restauração de solos contaminados com hidrocarbonetos de petróleo. Muitas espécies de microorganismos dos solos conseguem metabolizar derivados do petróleo reduzindo-os em $\mathrm{CO}_{2}$ e $\mathrm{H}_{2} \mathrm{O}$ (produtos de sua completa (produtos de suso caso, cerca de $50 \%$ da matéria orgânica é incorporada à biomassa e os outros $50 \%$ são transformados em dióxido de carbono. Dessa forma, o tota do contaminante consumido pode ser quantificado através da geração de $\mathrm{CO}_{2}$. Assim, o processo de biodegradação pode ser acompanhado por cromatografia gasosa, mediante a dosagem deste composto, utilizando detectores por condutividade térmica ou de infravermelho não-dispersivo. Portanto, o percentul de biodegradaça (PB) do 2 (Jaramillo, 1996). 2 (Jaramillo, 1996).

$P B(\%)=\left(C_{\text {consumido }} \times 100\right) / C_{i}$,
onde:

caso, se a fonte receptora não for atingida, não existe a a focssidade de implantação de métodos mais drásticos e, então, a ANM seria uma opção economicamente viável de recuperação da área contaminada. No entanto, se o processo de ANM
Qualquer prática de biorremediação que se baseia em processos de degradação de contaminantes orgânicos, deve ser iniciada com um extenso e cauteloso levantamento hidrogeológico, geoquímico e microbiológico da área contaminada. Dependendo das condições da região, a cinétic de biodegradação dos compostos será mais rápida ou mais lenta. As condicionantes do meio, devidamente estudadas, vão nortear não apenas a melho técnica de extração ou eliminação de contaminantes, como também a possibilidade de biodegradação dos poluentes, o que normalmente pode ocorrer como um polimento ou um incremento da remediação, com ou sem estímulo da microbiota diagnóstico da áeac, coma etapa prelininar de necessária, pois permite que os profissionais responsáveis pela remediação decidam, por exemplo, pelo uso de processos adicionais para acelerar a biorremediação ou, em alguns casos, para promover a atenuação natural monitorada. Neste últime te, nos casos em que uma análise exploratónia permite definir que a contaminação não representa riscos à sociedade, em curto, médio ou longo prazo. Dessa maneira, é de grande importância readeterminar a de degradação como forma de prever ate onde a pluma de contaminação irá se Drastra a Figura 7, quando a taxa

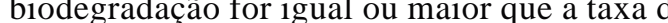
deslocamento dos contaminantes, a pluma deixa- 


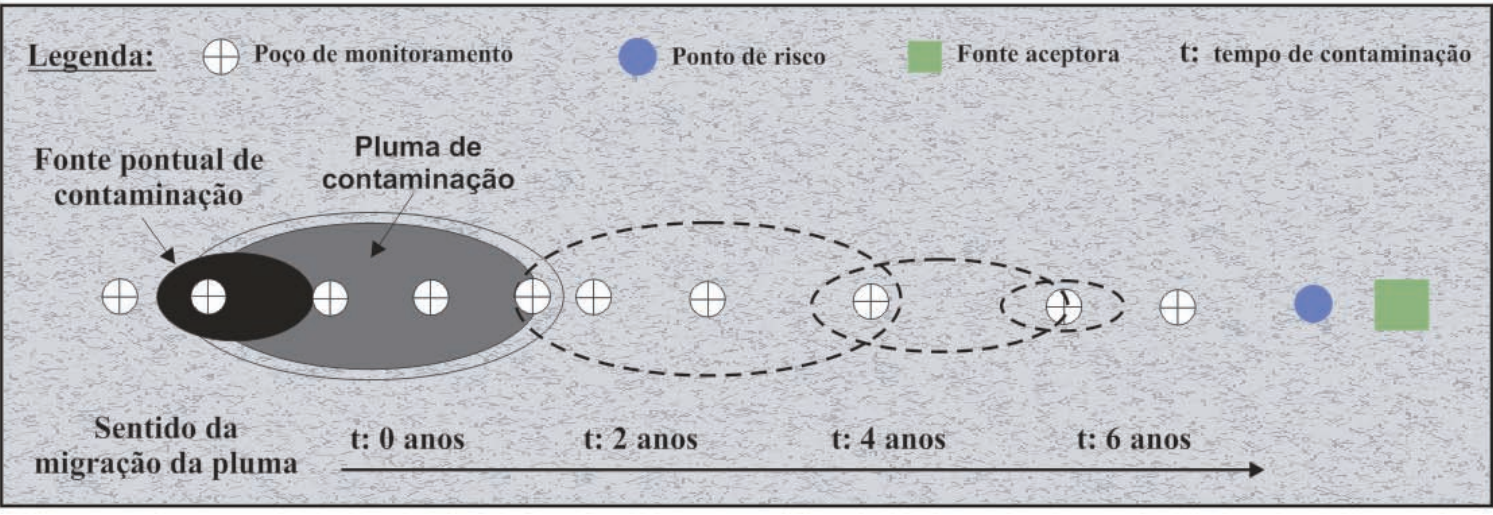

Figura 7. Exemplo da atenuação natural monitorada de uma pluma de hidrocarbonetos de petróleo

Portanto, trabalhos de diagnóstico correto e a implantação de um programa de ANM podem reduzir consideravelmente o custo da remediação e evitar uma nova intervenção humana no local contaminado. Com base nessa informac̃ão, não é por acaso que nos Estados Unidos, onde o mercado ambiental 作 contaminações causadas por vazamento de tanques de combustíveis subterrâneos é feita por atenuação natural monitorada, como mostram os dados da Figura 8 (EPA, 2004b).

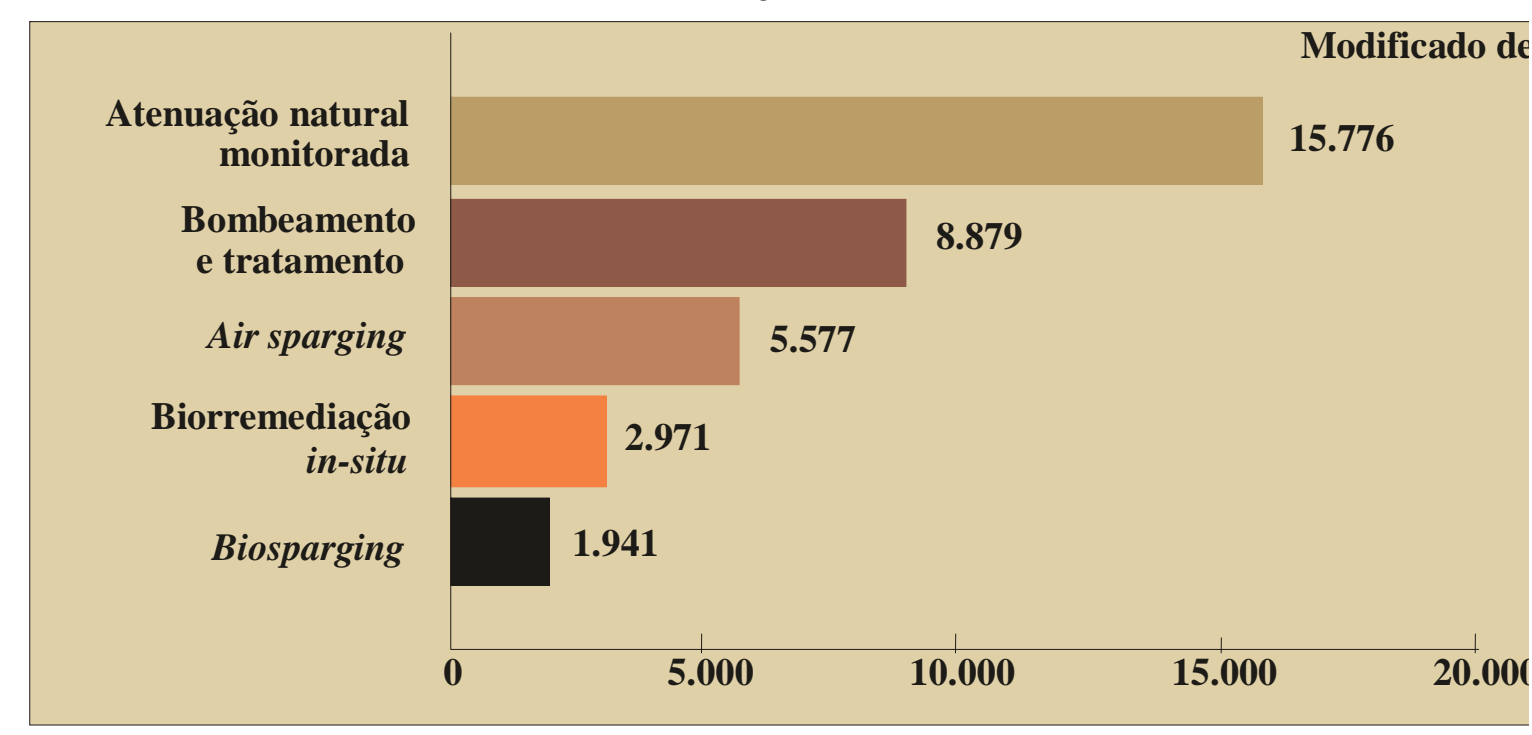

Figura . Número de locais contaminados por combustíveis procedentes do vazamento de tangues subterrâneos versus as diferentes técnicas de remediação empregadas para o tratamento desses tanques instalados nos EUA (EPA, 2004b)
Segundo a EPA (2004b), como apresentado na Figura 8, nos EUA há quase 16 mil casos de ANM utilizados em contaminações por tanques de combustíveis subterrâneos contra, aproxima-

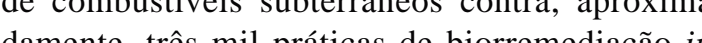
damente, três mil práticas de biontra, aproxĩa in-situ usadas con a mesma finalidade. Portanto, se não há risco que justifique pressa para a remediação da área contaminada por poluentes solúvei (alvo maior da bioestimulação) ou insolúveis, recomenda-se deixar a natureza se autodepurar, ou seja, optar pela atenuação natural. Ressalta-se, no entanto, que nos casos de adoção da técnica da atenuação natural, os custos envolvidos na fase de estudos podem ser bastante elevados, face à grande quantidade de informações necessárias r a tomada de decisão. É claro que todas essas informaços relacionadas aos custos e à eficiência da técnica deven ser ponderadas e estudadas em laboratórios, antes de qualquer aplicação em grande escala.

Uma outra possibilidade plausível de intervenção, conforme recomendada pela CETESB (2004), seria a alteração do uso e da ocupação do solo. Esta alternativa envolve os mesmos princípios da atenuação natural com monitoramento, com a diferença que, para garantir a ausência de riscos a saúd pública, ao ambiente e aos demais bens a proveger, faz-se necessária uma redefição ou restrição do uso do solo ná área a tada. Esta restric̃ão deve ser válida dura área a restrição deve ser válida durante o período no qual o programa de monitoramento seja mantido.

Segundo a CETESB (2006), os trabalhos envolvendo a biorremediação de solos, ocorren em maior número no Estado de São Paulo, onde a maior parte das áreas contaminadas, catalogadas por esta agência ambiental, são provenientes de vazamentos de tanques subterrâneos de postos de serviços. Em contus sones deste tipo, tem pre-

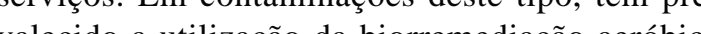
valecido a utilização da bionrentiação aeróbica in-situ. Entretanto, segundo Aislabie et al. (2006) vale considerar que vários fatores podem afetar eficiência das técnicas de biorremediação in-situ. Dentre eles, o oxigênio tem se revelado o fato limitante para microorganismos capazes de degradar aerobicamente contaminantes como o petróleo e seus derivados. Na ausência da concentração adequada de oxigênio, a degradação dos contaminantes irá cessar ou poderá proceder de forma constatado por alguns pesquisadores que o tratamento de solos utilizando as técnicas de biorremediação in-situ é tipicamente mais barato que os tratamentos ex-situ. Nos processos in-situ, há um mínimo de d 作 necessária a utilização de grandes equipamentos. Por outro lado, nos processo ex-situ, os trabalho que envolvem a remoção e o transporte das zona contaminadas, na maioria das vezes, é economicamente dispendioso, aumenta a exposição dos trabalhadores aos contaminantes e nem sempre conduz à destruição ou à redução da toxicidade dos compostos.

De modo geral, a biorremediação de solos apresenta-se como uma técnica bastante eficiente na degradação de petróleo e seus derivados, mesmo em condições ambientais extremas (Margesin \& Schinner, 2001). Isso pode ser comprovado facilmente pelo grande número de trabalhos publicados recentemente em periódicos de grande relevância para a comunidade científica. Não obstante à existência de alguns interferentes, como as condições ambientais (principalmente os teores de umidade e de aeração dos solos) e a disponibilidade de nutrientes, as vantagens como a relação custo-benefício e a eficiência de degradação de compostos tóxicos e recalcitrantes, têm feito com que essa técnica de remediação seja utilizada com frequência em vários países desenvolvidos. Porém, ao contrário do que tem acontecido no Estados Unidos, no Brasil os projetos de biorremediação e de atenuação natural monitorada ainda estão no campo da teoria, com poucos casos práticos, embora exista uma real probabilidade de expansão. No caso do Brasil, a biorremediação in-situ é favorecida pelas condições necessárias para a implementação de técnica, sobretudo, pelas condições climáticas típicas da maioria das regiões geográficas nacionais.

Portanto, frente ao exposto, é imperativo que o profissional responsável pela reabilitação da área apresente uma caracterização completa do local contaminado, identificando os tipos de contaminantes presentes, a delimitação da pluma de contaminação e uma avaliação correta do passivo ambiental existente não apenas na área visível, mas também, no subsolo. Essas informações de- 


\section{AGRADECIMENTOS}

Os autores agradecem ao CNPq pela concessão do auxílio financeiro.

Summary: In view of the proven efficiency of bioremediation in the degradation of compounds toxic to humans, such as benzene, toluene, ethylbenzene and xylenes (BTEX), several companies, especially those related to remediation and environmental monitoring, have shown enormous interest in the deployment of bioremediation as an option for the rehabilitation of contaminated areas. In developed countries such as the United States, Canada and severa European countries, these biochemical remediation techniques have been widely used in work that is based, for example, on the treatment of soil contaminated by petroleum hydrocarbons. However, contrary to what has been done in these countries, in Brazil, bioremediation projects are still mainly theoretical, with few practical cases, but there is a real likelihood of expansion. The more important aim of this review is to indicate the advantages that this technique can offer when it is used for the degradation of compounds such as BTEX in typical Brazilian soils, whose physico-chemical characteristics contribute to the degradation of contaminants. Research shows that environmental factors (such as moisture and oxygen levels) and the availability of soil nutrients, in addition to the climatic conditions in Brazil, are quite suitable for the employment of this technique. They may pose, as an advantage, a favorable cost/benefit ratio and the opportunity for greater efficiency in the degradation of toxic and recalcitran compounds compared to the majority of conventional remediation techniques. In summary, this review focuses on the state of the art of bioremediation techniques of contaminants in soils, presenting the most current and recent applications and innovations, as reported in the national and international media.

Index terms: bioremediation, degradation, contaminants, petroleum hydrocarbons - BTEX, soil.

\section{REFERÊNCIAS}

[1] ACTON, D.W. \& BARKER, J.F. In situ biodegradation potential of aromatic hydrocarbons in anaerobic groundwaters. J. Contam. Hydrol., 9:325-352, 1992.

[2] AELION, C.M. \& BRADLEY, P.M. Aerobic biodegradation potential of subsurface microorganisms fro a jet fuel-contaminated aquifer. Appl. Environ. Microbiol., 57:57-63, 1991.

[3] AISLABIE, J.; SAUL, D.J. \& FOGHT, J.M. Bioremediation of hydrocarbon-contaminated polar soi Extremophiles, 10:171-179, 2006

[4] WATERHOUSE, E.J. Hydrocarbon spills on Antarctic soils: effects and management. Environ. Sci. Technol., 38:1265-

[5], ALEANDER, M. Biodegradation and Bioremediation.
[10] BERNOTH, L.; FIRTH, I.; MCALLISTER, P. \& RHODES, S. Biotechnologies for remediation and pollution control in the mining industry. Miner. Metall. Proc., 17:105111, 2000

[11] BETANCUR-GALVIS, L.A.; BERNAL, D.A.; RAMOSVALDIVIA, A.C. \& DENDOOVEN, L. Bioremediation of polycyclic aromatic hydrocarbon-contaminated salinealkaline soils of the former Lake Texcoco. Chemosphere, 62:1749-1760, 2006.

[12] BOROLE, A.P.; SUBLETTE, K.L.; RATERMAN K.T.; JAVANMARDIAN, M. \& FISHER, J.B. The potentia for intrinsic bioremediation of BTEX hydrocarbons in soil/ ground water contaminated with gas condensate. Appl. Biochem. Biotech., 63-65:719-730, 1997.

[13] BROWN, R.A. In Situ Chemical Oxidation: Performance, Practice, and Pitfalls. AFCEE Technology Transfer Workshop, San Antonio, Texas, 2003. Disponível em: http://www. clu-in.org/techfocus/default.focus/sec/In_Situ_Oxidation/ download/techfocus/chemox/4_brown.pdf. Acesso em 06 mar. 2008.

[14] CETESB: COMPANHIA DE TECNOLOGIA DE SANEAMENTO AMBIENTAL. Avaliação do Uso de Produtos Biotecnológicos para Tratamento de Efluentes Liquidos, Resíduos Solidos e Remediação de Solos e Aguas - L1.022, 200\%. 21p. Disponive

sp.gov.br/. Acesso em 20 mar. 2008.

IIECNOLOGIA DE 103/2007///E, de 22 de junho de 2007, 2007a. 40p. Disponível 103/2007/L, de 22 de junho de 207, 2007 a. 40p. Disponive em: http://www.cetesb.sp.gov.br/. Acesso em 10 mar. 2008. SANEAMENTO AMBIENTAL Manul áreas contaminadas. 2.ed., 2001. 389p. [17] CETESB:- COMPANHTA DE

SECNOLOGIA DE

de áreas contaminads. Caṕtulo X Investigac̃an de áreas contaminadas. Capítulo X - Investigação para
Biorremediação, 2004. 77p.

[18] CETESB: COMPANHIA DE TECNOLOGIA DE SANEAMENTO AMBIENTAL. Relação de áreas contaminadas, 2006. Disponivel em: http://www.cetesb.
sp.gov.br/. Acesso em 07 mar. 2008.
[19] CETESB: COMPANHIA DE TECNOLOGIA DE

SANEAMENTO AMBIENTAL Relatório de estoGIA DE de valores orientadores para solos e águas subterrâneas no Estado de São Paulo, 2005. Disponível em: http://www. cetesb.sp.gov.br/. Acesso em 19 mar. 2008.

[20] CHEN, K.F.; KAO, C.M.; CHEN, T.Y.; WENG, C.H. \& TSAI, C.T. Intrinsic bioremediation of MTBE-contaminated groundwater at a petroleum-hydrocarbon spill site. Environ. Geol., 50:439-445, 2006

[21] CLU-IN: HAZARDOUS WASTE CLEAN-UP INFORMATION. Technology Practices Manual for Surfactants and Cosolvents. CH2MHILL, 2006. Disponível em: http://clu-in.org/. Acesso em 13 mar. 2008.

Ecl. Quím., São Paulo, 35 - 3: 17 - 43, 2010
[22] COLVIN, G.H. Biostimulation and bioaugmentation of recalcitrant VOCs in groundwater using Hydrogen Release Compound $\left(\mathrm{HRC}^{\circledR}\right.$ ) and bio-dechlor inoculum (BDI)”. P. In. In-situ and On-site Bioremediation, Battelle Press. 2005.

[23] COULON, F. \& DELILLE, D. Influence of substratum on the degradation processes in diesel polluted sub-Antarctic soils (Crozet Archipelago). Polar Biol., 29:806-812, 2006. [24] CUSTANCE, S.R.; MCCAW, P.A.; KOPF, A.C. \& SULLIVAN, M.J. Environmental fate of the chemical mixtures: crude oil, jp-5, mineral spirits, and diesel fuel. J. Soil Contam., 1:379-386, 1992.

[25] DELFINO, J.J. \& MILES, C.J. Aerobic and anaerobic degradation of organic contaminants in Florida groundwate Soil Crop Sci. Soc. Fl. Proc., 44:9-14, 1985.

[26] DigIULIO, D.C. \& VARADHAN, R. Developmen of recommendations and methods to support assessment of soil venting performance and closure. U.S. EPA, ORD, EPA/600/R-01/070, 2001

[27] DUA, M.; SINGH, A.; SETHUNATHAN, N. \& JOHRI, A.K. Biotechnology and bioremediation: successes Imitations. Appl. Microbiol. Biot., 59:143-152, 2002. [28] EMBAR, K., FORGACS, C. \& SIVAN, A. The role of indigenous bacterial and fungal soil populations in the biodegradation of crude oil in a desert soil. Biodegradatio

[2] ENVIRONMENTAL PROTECTION AGENCY - EPA. How to Evaluate Alternative Cleanup Technologies for Underground Storage Tank Sites: A Guide for Corrective Dispotiol Disposivel em. hitt://www.epa.gov/swerust1/pubs/tums.htm. EPA: ENVIRONM

MENTAL PROTECTION AGENCY 作 542-F-01-013, 2001a.

[31] EPA: ENVIRONMENTAL PROTECTION AGENCY, To Evaluate Alternative Cleanup Techologies for Underground Storage Tank Sites: A Guide Chemical Oxidation, EPA 510-B-94-003. ChA 510-B-95-007 and EPA 510-R-04-002, 2004a. 52p.

[32] EPA: ENVIRONMENTAL PROTECTION AGENCY, UNITED STATES. How to Evaluate Alternative Clean Technologies for Underground Storage Tank Sites: A Guide for Corrective Action Plan Reviewers. Chapter IX - Monitored Natural Attenuation, EPA 510-B-94-003; EPA 510-B-95-007 and EPA 510-R-04-002, 2004b. 77p.

[33] EPA: ENVIRONMENTAL PROTECTION AGENCY, UNITED STATES. How to Evaluate Alternative Cleanup Technologies for Underground Storage Tank Sites: A Guide for Corrective Action Plan Reviewers. Chapter II - Soil Vapo Extraction, EPA 510-B-94-003; EPA 510-B-95-007 and EPA 510-R-04-002, 2004c. 36p.

UNITED STATES. How to Evaluate Alternative Clean 
Technologies for Underground Storage Tank Sites: A Guide for Corrective Action Plan Reviewers. Chapter XII Enhanced Aerobic Bioremediation, EPA 510-B-94-003; EPA 510-B-95-007 and EPA 510-R-04-002, 2004d. 73p.

[35] EPA: ENVIRONMENTAL PROTECTION AGENCY, UNITED STATES. How to Evaluate Alternative Cleanup Technologies for Underground Storage Tank Sites: A Guide
for Corrective Action Plan Reviewers. Chapter IV - Biopiles, EPA 510-B-94-003; EPA 510-B-95-007 and EPA 510-R-04002, 2004e. 30p.

[36] EPA: ENVIRONMENTAL PROTECTION AGENCY, UNITED STATES. Integrated Risk Information System: benzene. CASRN 71-43-2, 2003a. Disponível em: http www.epa.gov/iris/subst/0276.htm. Acesso em 22 mar. 2008 [37] EPA: ENVIRONMENTAL PROTECTION AGENCY, UNITED STATES. Method 8260C: Volatile Organic Compounds by Gas Chromatography/Mass Spectrometry (GC/MS), 2006. Disponivel em: http://www.epa.gov/ epaoswer/hazwaste/test/new-meth.htm. Acesso em 24 m

[38] EPA: ENVIRONMENTAL PROTECTION AGENCY. A Citizen's Guide to Bioremediation, Soil Waste and Emergency Response, EPA 542-F-01-001, 2001b. Disponivel em: http www.epa.gov/. Acesso em 15 mar. 2008.

[30 ETA: EN. ACIONO Bioremediation in the field, 2003b. 39p. Disponível en: [40] FUKADA, S. \& TAKAGI, K. En. 2008.

of soil and groundwater at a petrol release site in Jatiation Int In-situ and On-site Bioremedition [11] $S$. Metabolic degradtion of methl tert-butyl ether by a soil S. Metabolic degradation of methyl tert-butyl ether by a soil Appl. Microbiol, 46:79-84, 2000. [42] HAWROT, M. \& NOWAK,

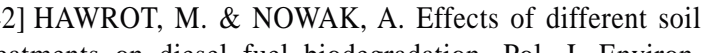
biodegradation. Pol. J. Environ.

[43] HUTCHINSON, S.L.; SCHWAB, A.P. \& BANKS, M.K. Blodegradation of petroleum hydrocarbons in the
rhizosphere. In: MCCUTCHEON, S.C. \& SCHNOOR J.L., ed. Phytoremediation - Transformation and control of contaminants. Hoboken, New Jersey, John Wiley, 2003. p. $355-386$.

[44] IARC: INTERNATIONAL AGENCY FOR RESEARCH ON CANCER. Carcinogenicity evaluation of BTEX, 71:829, 2006. Disponivel em: htpp:/wwwiarc fr/. Acesso em: 14 mar. 2008.

[45] JARAMILLO, I.R. Fundamentos teóricos-práticos de temas selectos de la ciência Del sueco. Parte 1, Universidad Autônoma Metropolitana, México. Apud: OLIVEIRA, F.R. \& MILLIOLI, V.S. Utilização de técnica de bioestímulo, avaliando-se parâmetros como relação nutricional e umidade na biorremediação de solo contaminado com óleo cru. XIII J.I.C., CETEM, 1996.
[46] KOENNIGSBERG, S.S. \& WILLETT, A. Accelerated bioremedation with oxygen release compound advanced: evolution of time-release electron acceptors. P. Int. In-situ and On-site Bioremediation. Battelle Press, 2005.

47] MAILA, M.P. \& CLOETE, T.E. The use of biologica activities to monitor the removal of fuel contaminantsperspective for monitoring hydrocarbon contamination: review. Int. Biodeter. Biodegr., 55:1-8, 2005.

[48] MARGESIN, R. \& SCHINNER, F. Biodegradation and bioremediation of hydrocarbons in extreme environments. Appl. Microbiol. Biot., 56:650-663, 2001.

49] MARÍN, J.A.; MORENO, J.L.; HERNÁNDEZ, T. \& GARCÍA, C. Bioremediation by composting of heavy oil refinery sludge in semiarid conditions. Biodegradation, 7:251-261, 2006.

[50] MORGAN, R. \& WATKINSON, R.J. Hydrocarbo degradation in soils and methods for soil treatment. CRC Crit. Rev. Biotechnol., 8:305-333, 1989.

[51] NAKAGAWA, L.E. \& ANDRÉA, M.M. Efeito de alterações nas características do solo sobre a degradação de hexaclorobenzeno. Rev. Bras. Ciên. Solo, 30:575-582, 2006. [52] NANO, G., BORRONI, A. \& ROTA, R. Combined slurry and solid phase bioremediations of diesel contaminated soil. . Hazard. Mater., B100:79-94, 2003.

FOR Carcinogen List, 2006. Disponível Carcinogen List, 2006. Disponivel em: http://0-www.cdc.gov. Cons.sjlibrary.org/niosh/honepage

JRC: NATIONAL RESEARCH COUNCIL. In Sit Bioremediation: When Does It Work? Washington, DC, National Academy Press, 1993.

[55] OU, Z. Separate and combined environmental behaviou of surfactants and polycyclic aromatic hydrocarbons (PAHs).

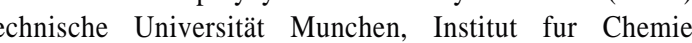
Lehrstuhl fur Ökologische Chemie und Umweltanalytik, 2000. 272f. (Tese de Doutorado).

[56] PERALTA-ZAMORA, P. \& TIBURTIUS, E.R.L. Contaminacão de águas por BTXs e processos utilizados na remediação de sítios contaminados. Quím. Nova, 27:441-446, 2004.

[57] RAHMAN, K.S.M.; BANAT, I.M. \& THAHIRA, J. Bioremediation of gasoline contaminated soil by a bacterial consortium amended with poultry litter, coir pith and rhamnolipid biosurfactant. Bioresour. Technol., 81:25-32, 2002.

[58] REED, T.A. Bioremediation of total petroleum hydrocarbons at a DOD site in Tracy, California. P. Int. In-situ and On-site Bioremediation. Battelle Press, 2004.

[59] ROBB, J. \& MOYER, E. Natural attenuation of benzene and MTBE at four midwestern retail gasoline marketing outlets. Contam. Soil Sed. Water, Spring:67-71, 2001.

[60] SÁNCHEZ, O.; FERRERA, I.; VIGUÉS, N.; OTEYZA, T.G.; GRIMALT, J.O. \& MAS, J. Presence of opportunistic oil-degrading microorganisms operating at the initial steps of oil extraction and handing. Int. Microbiol., 9:119-124, 2006. [61] SAUL, D.J.; AISLABIE, J.; BROWN, C.E.; HARRIS, L. \& FOGHT, J.M. Hydrocarbon contamination changes the bacterial diversity of soil from around Scott Base, Antarctica. FEMS Microbiol. Ecol., 53:141-155, 2005.

[62] SCHWARZENBACH, R.P.; GSCHWEND, P.M. \& IMBODEN, D.M. Environmental Organic Chemistry. New York, John Wiley, 1993. p.682.

[63] SHUHONG, Y.; LEICHANG, H.; LI, Y.O.; MING, D.; YINGYING, H. \& DEWEEN, D. Investigation on bioremediation of oil-polluted wetland at Liaodong Bay in northeast China. Appl. Microbiol. Biot., 71:543-548, 2006. [64] SILVA, E.; FIALHO, A.M.; SA-CORREIA, I.; BURNS, R.G. \& SHAW, L.J. Combined bioaugmentation and biostimulation to cleanup soil contaminated with high concentrations of atrazine. Environ. Sci. Technol., 38:632 637, 2004.

65] SIMS, J.L.; SUFLITA, J.M. \& RUSSELL, H.H. Groun water issue: In situ bioremediation of contaminated groun water, EPA/540/S-92/003, U.S. Environmental Protection Agency Office of Solid Whs. Envil 1992. 11p.

(66) TATE, R.L. Soil Microbiology. New York, John Wiley,

[67] TOP, E.M. \& SPRINGAEL, D. The role of mobile genetic elements in bacterial adaptation to xenobiotic organic compounds. Curt. Opin. Blocechol., 14.262-269, 2003. Evidence for the 0 ., LArrence of sil bior for dition by solid-state fermentation. Biochen. Eng. J., 13:103-112, 2003. [69! TSAO, C.W. SONG,

作, M.G. \& BARTHA, R. Metabolism OF

Biopiles of POL (petroleum, oils, anMENTAL CENTER. (7) aec.army.mil/usaec/. Acesso em 14 mar. 2008.

[71] USAEC: U.S. ARMY ENVIRONMENTAL CENTER, Intrinsic Remediation of POL (petroleum, oils, and lubricants) Contaminated Sites, Restoration Technology, 2003b. Disponível em: http://aec.army.mil/usaec/. Acesso en 15 mar. 2008.

[72] VAN DER HOEK, J.P.; URLINGS, L.G.C.M. \& GROBBEN, C.M. Biological removal of polycyclic aromatic hydrocarbons, benzene, toluene, ethylbenzene, xylene an phenolic compounds from heavily contaminated ground water and soil. Environ. Technol. Lett., 10:185-194, 1989 .

73] VIDALI, M. Bioremediation. An overview. Pure Appl. Chem., 73:1163-1172, 2001

[74] VROM. Intervention values and target values: soil quality standards. Ministry of Housing, Spatial Planning and Environment. Premises for risk management: annex to the
Dutch Environmental Policy Plan. The Hague: Lower House, DBO/07494013, 1994. 19p

[75] WATTS, R.J.; HALLER, D.R.; JONES, A.P. \& TEEL, A.L. A foundation for the risk-based treatment of gasolin contaminated soils using modified Fenton's reactions. Hazard. Mater., 76:73-89, 2000.

[76] WYNM, J.L. Monitored natural attenuation with oxygen release material. P. Int. In-situ and On-site Bioremediation Battelle Press, 2003. 